NBER WORKING PAPER SERIES

\title{
CONSUMPTION RISK-SHARING AND THE REAL EXCHANGE RATE: WHY DOES THE NOMINAL EXCHANGE RATE MAKE SUCH A DIFFERENCE?
}

\author{
Michael B. Devereux \\ Viktoria Hnatkovska \\ Working Paper 17288 \\ http://www.nber.org/papers/w17288
}

\author{
NATIONAL BUREAU OF ECONOMIC RESEARCH \\ 1050 Massachusetts Avenue \\ Cambridge, MA 02138
}

August 2011

We are grateful to Margarida Duarte, Charles Engel, and participants at various conferences and institutions for comments and suggestions. We also thank Marco del Negro for kindly sharing state-level consumption and price data for the US with us. Matias Cortes provided excellent research assistance. Hnatkovska thanks SSHRC for research support. Devereux thanks SSRHC, the Bank of Canada, and the Royal Bank of Canada for financial support. The opinions expressed in this paper are those of the authors alone and cannot be ascribed to the Bank of Canada. The views expressed herein are those of the authors and do not necessarily reflect the views of the National Bureau of Economic Research.,

NBER working papers are circulated for discussion and comment purposes. They have not been peerreviewed or been subject to the review by the NBER Board of Directors that accompanies official NBER publications.

(C) 2011 by Michael B. Devereux and Viktoria Hnatkovska. All rights reserved. Short sections of text, not to exceed two paragraphs, may be quoted without explicit permission provided that full credit, including $\odot$ notice, is given to the source. 
Consumption Risk-Sharing and the Real Exchange Rate: Why does the Nominal Exchange

Rate Make Such a Difference?

Michael B. Devereux and Viktoria Hnatkovska

NBER Working Paper No. 17288

August 2011

JEL No. F3,F4

\begin{abstract}
A basic prediction of effcient risk-sharing is that relative consumption growth rates across countries or regions should be positively related to real exchange rate growth rates across the same areas. We investigate this hypothesis, employing a newly constructed multi-country and multi-regional data set. Within countries, we find signifcant evidence for risk sharing: episodes of high relative regional consumption growth are associated with regional real exchange rate depreciation. Across countries however, the association is reversed: relative consumption and real exchange rates are negatively correlated. We identify this failure of risk sharing as a border effect. We find that the border effect is substantially (but not fully) accounted for by nominal exchange rate variability. We then ask whether standard open economy macro models can explain these features of the data. We argue that they cannot. To explain the role of the nominal exchange rate in deviations from cross country consumption risk sharing, it is necessary to combine multiple sources of shocks, ex-ante price setting, and incomplete financial markets.
\end{abstract}

Michael B. Devereux

Department of Economics

University of British Columbia

997-1873 East Mall

Vancouver, BC V6T 1Z1

CANADA

and NBER

mbdevereux@gmail.com

Viktoria Hnatkovska

Department of Economics

University of British Columbia

Vancouver, BC V6T 1Z1

hnatkovs@interchange.ubc.ca 


\title{
Consumption Risk Sharing and the Real Exchange Rate: Why Does the Nominal Exchange Rate Make Such a Difference?*
}

\author{
Michael B. Devereux ${ }^{\dagger}$ and Viktoria Hnatkovska ${ }^{\ddagger}$
}

August 2, 2011

\begin{abstract}
A basic prediction of efficient risk-sharing is that relative consumption growth rates across countries or regions should be positively related to real exchange rate growth rates across the same areas. We investigate this hypothesis, employing a newly constructed multi-country and multi-regional data set. Within countries, we find significant evidence for risk sharing: episodes of high relative regional consumption growth are associated with regional real exchange rate depreciation. Across countries however, the association is reversed: relative consumption and real exchange rates are negatively correlated. We identify this failure of risk sharing as a 'border' effect. We find that the border effect is substantially (but not fully) accounted for by nominal exchange rate variability. We then ask whether standard open economy macro models can explain these features of the data. We argue that they cannot. To explain the role of the nominal exchange rate in deviations from cross country consumption risk sharing, it is necessary to combine multiple sources of shocks, ex-ante price setting, and incomplete financial markets.
\end{abstract}

JEL Classification: F3, F4

Keywords: Real exchange rate, risk sharing, border effect, intranational economics

\section{Introduction}

Many studies of aggregate consumption behavior have documented the failure of naive models of consumption risk-sharing. This is true both within countries (risk-sharing across provinces or states) and across countries. Recognizing that relative consumption prices are time-varying leads to a more elaborate test for consumption risk-sharing, incorporating both within and between country

\footnotetext{
${ }^{*}$ We are grateful to Margarida Duarte, Charles Engel, and participants at various conferences and institutions for comments and suggestions. We also thank Marco del Negro for kindly sharing state-level consumption and price data for the US with us. Matias Cortes provided excellent research assistance. Hnatkovska thanks SSHRC for research support. Devereux thanks SSRHC, the Bank of Canada, and the Royal Bank of Canada for financial support. The opinions expressed in this paper are those of the authors alone and cannot be ascribed to the Bank of Canada.

${ }^{\dagger}$ Department of Economics, University of British Columbia, 997 - 1873 East Mall, Vancouver, BC V6T 1Z1, Canada; CEPR; NBER. E-mail address: devm@interchange.ubc.ca.

${ }^{\ddagger}$ Department of Economics, University of British Columbia, 997 - 1873 East Mall, Vancouver, BC V6T 1Z1, Canada. E-mail address: hnatkovs@interchange.ubc.ca.
} 
real exchange rates movements. The prediction of this extended model is that relative consumption growth rates (across regions or countries) are highly correlated with movements in real exchange rates. We test this hypothesis using a novel multi-country and multi-regional data set. We show that a sharp dichotomy arises between within-country and across-country comparisons, particularly for across-country groups that have flexible bilateral exchange rates. Within countries, movements in real exchange rates tend to support the hypothesis of some (imperfect) risk-sharing. Across countries however, the real exchange rate plays either no role or a negative role in risk-sharing. This is essentially the well-known 'Backus Smith' puzzle (Backus and Smith, 1993). This is particularly true of countries that exhibit substantial fluctuations in nominal exchange rates. ${ }^{1}$ Thus, the failure of across-country (as opposed to within-country) risk sharing is proximately due to movements in nominal exchange rates. Countries (or regions) with fixed exchange rates tend to exhibit relative consumption growth rates that are positively correlated with national (or regional) real exchange rates. But in countries with substantial fluctuations in nominal exchange rates the correlation tends to be negative. Can this finding be reconciled with standard models of real exchange rate determination? This paper is an attempt to resolve this question.

We note that this is not quite the same as an attempt to resolve the Backus-Smith puzzle, or 'consumption - real exchange rate anomaly' (see Chari, Kehoe, and McGrattan, 2002). Studies that have offered convincing resolutions of this anomaly (see below for a discussion) typically do not make any predictions about the behavior of the nominal exchange rate. Therefore, these studies imply that the relationship between relative consumption and the real exchange rate should be unaffected by the nominal exchange rate regime.

We begin by providing a comprehensive empirical account of the role of the real exchange rate in regional and international risk sharing in a large intra-national and international dataset. The dataset contains consumption and bilateral consumption prices (or real exchange rates) at the provincial or state level for a group of countries. We show that for all countries in the sample, there is evidence that the real exchange rate plays a positive role in within country risk-sharing. That is, consumption growth differences across provinces or states are positively correlated with bilateral real exchange rate changes across the same geographical units. But when we include a 'border dummy' in the risk sharing regression, indicating that relative consumption growth involves comparisons across countries, the overall relationship between consumption growth and real exchange rate changes falls dramatically, and in most cases is negative. Further investigation reveals that most, (but not all) of this border effect can be attributed to nominal exchange rate volatility. ${ }^{2}$

We then ask, are these results consistent with standard models of international risk sharing and real (and nominal) exchange rate volatility? Most proposed resolutions of the Backus-Smith anomaly have emphasized the joint role of incomplete markets and shocks which generate strong income effects. The intuition is that a country which has a faster growing consumption experiences an appreciating real exchange rate (e.g. Corsetti, Dedola, and Leduc, 2008). But when we extend

\footnotetext{
${ }^{1}$ See also Hess and Shin (2010) and Hadzi-Vaskov (2008).

${ }^{2}$ Note that we refer to the "border" broadly defined as a separation between any two countries.
} 
the anomaly to encompass both regions within a country, and the importance of the nominal exchange rate, these explanations are not complete, since in the standard models, these shocks tend to produce negative consumption real-exchange rate correlations across regions within a country, or across countries, independently of how the nominal exchange rate is determined. In order to adequately explain the data, it is necessary to allow for a non-trivial role for the nominal exchange rate regime in consumption risk-sharing, since the evidence indicates that the failure of risk-sharing (or equivalently, the large role played by the border) is strongly tied to movements in the nominal exchange rate.

We show that the standard sticky price international macro model cannot account for these features of the data. This is because, despite allowing for a non-trivial role for the nominal exchange rate regime, the model generically implies that if there is a negative correlation between relative consumption growth and the real exchange rate, it will occur equally under fixed or flexible exchange rates. In fact, to the extent that states (or provinces) are analogous to countries within a fixed exchange rate area, the standard model also predicts a negative correlation between relative consumption growth and real exchange rates between states; the presence of the nominal exchange rate in itself does not alter the implication of these models. The essential reason that the standard sticky price model cannot account for the empirical regularities in the data is that in fact, the (co)-variance properties of the real exchange rate in this model are only slightly affected by the exchange rate regime itself. Essentially the reason is that in these models, although prices are nominally sticky, they are forward looking, and price adjustment may be substantially enhanced by the absence of nominal exchange rate adjustment, so that the absence of nominal exchange rate adjustment is compensated for by additional nominal price adjustment.

The critical requirement in explaining the pattern of correlations in the data is to allow for shocks which cause relative consumption growth to rise and the nominal exchange rate to simultaneously appreciate under flexible exchange rates, but which leave relative inflation rates unchanged (or to increase) under fixed exchange rates. The paper goes on to show one way that this can be done in an amended form of the standard sticky price open-economy framework. We do this by combining the basic model with a number of elements. In particular, we employ the assumptions of a) incomplete financial markets (limited by trade in non-contingent bonds), b) ex-ante staggered price setting in both countries, and c) 'demand-type' shocks which simultaneously increase relative consumption while generating a real exchange rate appreciation. We show that this combination leads to a model in which movements in the nominal exchange rate may be dominated by demand shocks, causing relative consumption and the real exchange rate to move in opposite directions, while, controlling for the nominal exchange rate, movements in the real exchange rate attributable to relative inflation rates lead relative consumption and the real exchange rate to move in the same direction. If demand shocks play a significant enough role, then the model predicts that under flexible exchange rates, the correlation between relative consumption growth and the real exchange rate will be negative. But fixing the exchange rate produces a positive correlation.

Thus, in principle, we can answer the question of the title - the role of the border in cross 
country consumption risk sharing is crucially tied to the nominal exchange rate regime, and the exchange rate displays characteristics in the model which are akin to those seen in the data.

\section{Estimating the border effect}

\subsection{Key theoretical relationship}

In this section, we present a general model of risk-sharing without additional features of production, sticky prices, etc., that are explored in section (3) below. To obtain key risk-sharing relationships, consider a multi-jurisdiction (where a jurisdiction may be a country or region) stochastic model. The utility of a representative household in jurisdiction $j=1, . ., J$ is given by:

$$
E_{t} \sum_{s=0}^{\infty} \beta^{s} U\left(C_{j, t+s}, \xi_{j, t+s}\right), \quad \beta<1
$$

where $\beta$ is the subjective discount factor, $C_{j, t}$ denotes a composite consumption good in country $j$. Here $\xi_{j, t}$ represents a jurisdiction specific factor which can affect the marginal utility of consumption, apart from consumption itself. This could represent pure preference shocks, or movements in workhours when households have non-separable utility. Define $P_{j, t}$ to be the price of a representative consumption basket in jurisdiction $j$ in period $t$. Also let $S_{t}^{i, j}$ be the exchange rate that converts prices from country $j$ 's currency to country $i$ 's currency in period $t$. If jurisdictions are within the same country, then $S_{t}^{i, j}=1$. Then the real exchange rate between any two regions $i$ and $j$ in different countries is given by $R E R_{t}^{j, i}=S_{t}^{i, j} P_{j, t} / P_{i, t}$, or $R E R_{t}^{j, i}=P_{j, t} / P_{i, t}$ if $i$ and $j$ are two regions in the same country.

Suppose that there is a complete set of state-contingent securities available to households in all countries. In this case, the key optimality condition is to equate marginal utilities of consumption across countries (or regions), adjusted for differences in price levels, evaluated in a common currency:

$$
U_{c}\left(C_{i, t}, \xi_{i, t}\right) R E R_{t}^{j, i}=U_{c}\left(C_{j, t}, \xi_{j, t}\right)
$$

This equation must hold in every date and state of the world, between any two countries or regions $i$ and $j$. It says that in equilibrium, consumption between households $i$ and $j$ must be allocated in a way that marginal utility (converted into the same units using the real exchange rate) is equalized across countries. Say now that $\xi_{j, t}=1$ for all $t .^{3}$ Then if utility is of a constant relative risk aversion (CRRA) form, with the coefficient of relative risk aversion $\sigma$, equation (2.1) becomes

$$
\left(\frac{C_{i, t}}{C_{j, t}}\right)^{\sigma}=R E R_{t}^{j, i}
$$

or equivalently in logs

$$
\sigma\left(\ln C_{i, t}-\ln C_{j, t}\right)=\ln R E R_{t}^{j, i} .
$$

\footnotetext{
${ }^{3}$ In the simplest version of the theoretical model below, we will re-introduce preference shocks.
} 
The expression above must also hold in growth rates:

$$
\sigma\left(\Delta \ln C_{i, t}-\Delta \ln C_{j, t}\right)=\Delta \ln R E R_{t}^{j, i}
$$

where $\Delta \ln X_{i, t}=\ln X_{i, t}-\ln X_{i, t-1}$. These expressions establish the close relationship between the real exchange rate and relative consumption between jurisdictions $i$ and $j$. In particular, it implies that consumption growth between $t-1$ and $t$ should be relatively higher in jurisdictions whose real exchange rates depreciate during the same period. Therefore, if markets are complete, the correlation, $\rho_{e, c_{j} / c_{i}}=\operatorname{corr}\left(\Delta \ln R E R_{t}^{j, i}, \sigma \Delta \ln \frac{C_{j, t}}{C_{i, t}}\right)$, should be equal to 1 , as pointed out by Backus and Smith (1993) and Kollmann (1995). A version of condition (2.2), defined in terms of conditional expectations, will also hold even under incomplete markets, so long as some financial assets can be traded across countries (see e.g. Obstfeld and Rogoff (1996)). Notice that if relative purchasing power parity (PPP) holds, so that RER is constant, then $\Delta \ln R E R_{t}^{j, i}=0$. In this case we get a standard risk-sharing result that consumption growth rates should be equal across jurisdictions. This simple implication has been tested extensively in the cross-country context in Asdrubali, Sørensen, and Yosha (1996), Athanasoulis and van Wincoop (2001), Bayoumi and Klein (1997), Hess and Shin (1998), Del Negro (2002), Van Wincoop (1995), Crucini (1999), and others.

\subsection{Evidence from US states and Canadian provinces}

Equation (2.2) gives us the key testable relationship implied by the model. As is clear from (2.2), the condition can be applied to any two locations of interest: countries, regions, states/ provinces/ prefectures, etc. We use this relationship to study the extent of national and regional risk-sharing between the US, Canada, Germany, Japan and Spain. ${ }^{4}$ We begin by focusing on just the US and Canada. This allows us to investigate the impact of the border on risk sharing in a similar manner to studies of deviations of the law of one price across regions within the US and Canada (Engel and Rogers (1996), Gorodnichenko and Tesar (2009)). In the next sub-section we investigate the same question for all five countries in our sample.

We employ intra-national data on consumption, output and prices in 50 US states during 19692006 and in 12 Canadian provinces and territories during 1981-2007. ${ }^{5}$ Using this data we compute all possible unique bilateral pairs of differences between log consumption, price and output growth rates. The pairs of states within the US we denote by UU, the pairs of provinces within Canada - by CC and state-province pairs by UC. The summary statistics for our two-country dataset are reported in Table 1. Note that, as to be expected, within country real exchange rates are much less volatile than across country real exchange rates. Table 1 also reveals another interesting characteristic of our intra-national data: Standard deviation of relative consumption growth within

\footnotetext{
${ }^{4}$ These are the countries for which we found historical jurisdiction-level data on consumption and prices. Details on data sources are provided in the Appendix A.1.

${ }^{5}$ For the US we use retail sales to proxy for private consumption; we construct state-level price indices using consumer price index (CPI) for main metropolitan areas and rural/urban prices; and use Gross State Product to measure output in the 50 states. In all other countries we use final consumption and output from regional accounts and regional consumer price indices. Data details are provided in the Appendix A.1.
} 
the US and Canada is significantly higher than the standard deviation of their relative price growth, while the opposite is true for cross-border location pairs.

Table 1: Sample summary statistics

\begin{tabular}{|c|c|c|c|c|c|}
\hline Variable & $\begin{array}{c}\text { Obs } \\
\text { (i) }\end{array}$ & $\begin{array}{l}\text { Mean } \\
\text { (ii) }\end{array}$ & $\begin{array}{l}\text { Std. Dev. } \\
\text { (iii) }\end{array}$ & $\begin{array}{l}\text { Min } \\
\text { (iv) }\end{array}$ & $\begin{array}{c}\operatorname{Max} \\
(\mathrm{v})\end{array}$ \\
\hline \multicolumn{6}{|l|}{ Panel 1: US } \\
\hline$\Delta \ln C_{i, t}-\Delta \ln C_{j, t}$ & 41650 & 0.0001 & 0.0551 & -0.4472 & 0.3859 \\
\hline$\Delta \ln Y_{i, t}-\Delta \ln Y_{j, t}$ & 41650 & 0.0000 & 0.0457 & -0.3624 & 0.4277 \\
\hline \multicolumn{5}{|l|}{ Panel 2: Canada } & 0.0999 \\
\hline$\Delta \ln C_{i, t}-\Delta \ln C_{j, t}$ & 1674 & 0.0015 & 0.0182 & -0.0680 & 0.1114 \\
\hline$\Delta \ln Y_{i, t}-\Delta \ln Y_{j, t}$ & 1674 & 0.0020 & 0.0557 & -0.2988 & 0.4390 \\
\hline $\begin{array}{l}\Delta \ln R E R_{t}^{j, i} \\
\text { Panel 3: US-Canada }\end{array}$ & 1674 & 0.0006 & 0.0095 & -0.0331 & 0.0342 \\
\hline$\Delta \ln C_{i, t}-\Delta \ln C_{j, t}$ & 13000 & -0.0025 & 0.0432 & -0.2852 & 0.3662 \\
\hline$\Delta \ln Y_{i, t}-\Delta \ln Y_{j, t}$ & 13000 & 0.0042 & 0.0515 & -0.2815 & 0.7279 \\
\hline$\Delta \ln R E R_{t}^{j, i}$ & 13000 & 0.0009 & 0.0551 & -0.1604 & 0.1588 \\
\hline $\begin{array}{l}\text { Notes: The table report } \\
\text { pairs (Panel 1); all Can } \\
\text { the number of observati } \\
\text { Min-sample minimum; }\end{array}$ & $\begin{array}{l}\text { mary } \\
\text { anada } \\
\text { each } \\
\text { ample }\end{array}$ & $\begin{array}{l}\text { cs of th } \\
\text { ce pairs } \\
\text { Mean - } \\
\text { um. }\end{array}$ & $\begin{array}{l}\text { ited var } \\
2 \text { ); all } \\
\text { average }\end{array}$ & $\begin{array}{l}\text { for three } \\
\text { ada pair } \\
\text { Dev. - s }\end{array}$ & $\begin{array}{l}\text { ll US-US state } \\
\text {. Obs. refer to } \\
\text { dard deviation; }\end{array}$ \\
\hline
\end{tabular}

To simplify our notation we will use $\Delta c_{t}^{i, j}$ to denote relative consumption growth between two locations $i$ and $j$, so that $\Delta c_{t}^{i, j}=\Delta \ln C_{i, t}-\Delta \ln C_{j, t}$; and $\Delta e_{t}^{j, i}$ to denote real exchange rate growth between locations $i$ and $j$, so that $\Delta e_{t}^{j, i}=\Delta \ln R E R_{t}^{j, i}$. Then based on equation (2.2) we posit the following specification to link relative consumption growth and real exchange rate growth:

$$
\Delta c_{t}^{i, j}=\beta_{0}+\beta_{1} \Delta e_{t}^{j, i}+\beta_{2}\left(\Delta e_{t}^{j, i} * \operatorname{border}_{i, j}\right)+v_{t}^{i, j},
$$

where $v_{t}^{i, j}$ is the error term arising due to preference shocks, measurement error, etc. border $r_{i, j}$ is the border dummy that takes value of one for all UC location pairs, and a value of zero otherwise. This allows us to focus on the distinction between cross country risk sharing and cross region risk sharing.

This specification restricts the relationship between the real exchange rate and relative consumption to be the same for any two locations in the US, in Canada or any two locations between the US and Canada. However, it is plausible to posit that the same change in the real exchange rate could be associated with different movements in relative consumption depending on the particular locations observed. In the theoretical model below for instance, we allow for preference shocks which may differ between any two locations. But more generally there may be differences in the degree of openness in goods or financial markets between two jurisdictions that are not reflected in changes in the real exchange rate. Distance represents a natural explanatory variable in the studies of the deviations from the law of one price between location pairs. In terms of deviations from risk sharing, distance may seem somewhat less compelling, since a) it may already be incorporated in the movement in real exchange rates, and b) it is a constant, and may not affect the risk sharing relationship when measured in growth rates. Nevertheless, some studies (e.g. Portes and Rey (2005), Okawa and van Wincoop (2010)) have documented the explanatory power of gravity 
type variables in accounting for financial market integration. To allow for this, we thus amend the basic relationship so as to allow for a distance measure, as in the gravity literature. Our benchmark model specification thus becomes

$$
\Delta c_{t}^{i, j}=\beta_{0}+\beta_{1} \Delta e_{t}^{j, i}+\beta_{2}\left(\Delta e_{t}^{j, i} * \operatorname{border}_{i, j}\right)+\beta_{3} \Delta e_{t}^{j, i} * \ln \tilde{d}_{i, j}+v_{t}^{i, j},
$$

where $\ln \tilde{d}_{i, j}$ is the normalized log distance between any two locations $i$ and $j$, defined as $\ln \tilde{d}_{i, j}=$ $\ln d_{i, j}-\overline{\ln d_{i, j}}$. Here $d_{i, j}$ is the distance between locations $i$ and $j$, which we proxy using the distance between the capital cities of the US states and Canadian provinces; while $\overline{\ln d_{i, j}}=7.69$ is the average log distance between all UC pairs. ${ }^{6}$ This normalization implies that $\ln \tilde{d}_{i, j}$ is equal to zero at $\ln d_{i, j}=\overline{\ln d_{i, j}}$, and simplifies interpretation of the $\beta_{2}$ coefficient, which now expresses the average effect of the border for the consumption-RER relationship between any two locations that are $\overline{\ln d_{i, j}}$ kilometers away. The interaction term between the real exchange rate and distance allows the relationship between $\Delta c_{t}^{i, j}$ and $\Delta e_{t}^{j, i}$ to change monotonically with the distance.

Table 2: Estimates of Border Effect: US-Canada

\begin{tabular}{|c|c|c|c|c|}
\hline & $\begin{array}{l}\text { Pooled } \\
\text { (i) }\end{array}$ & $\begin{array}{l}\text { Fixed effects } \\
\text { (ii) }\end{array}$ & $\begin{array}{l}\text { Pooled } \\
\text { (iii) }\end{array}$ & $\begin{array}{l}\text { Fixed effects } \\
\text { (iv) }\end{array}$ \\
\hline$\Delta e_{t}^{j, i}$ & $\begin{array}{c}0.429^{* * *} \\
(0.023)\end{array}$ & $\begin{array}{c}0.424^{* * *} \\
(0.026)\end{array}$ & $\begin{array}{c}0.319^{* * *} \\
(0.023)\end{array}$ & $\begin{array}{c}0.317^{* * *} \\
(0.027)\end{array}$ \\
\hline$\Delta e_{t}^{j, i} *$ border $_{i, j}$ & $\begin{array}{c}-0.451^{* * *} \\
(0.024)\end{array}$ & $\begin{array}{c}-0.447^{* * *} \\
(0.027)\end{array}$ & $\begin{array}{c}-0.348^{* * *} \\
(0.024)\end{array}$ & $\begin{array}{c}-0.345^{* * *} \\
(0.027)\end{array}$ \\
\hline$\Delta e_{t}^{j, i} * \ln \tilde{d}_{i, j}$ & $\begin{array}{c}-0.054^{* * *} \\
(0.011)\end{array}$ & $\begin{array}{c}-0.055^{* * *} \\
(0.012)\end{array}$ & $\begin{array}{c}-0.047 * * * \\
(0.011)\end{array}$ & $\begin{array}{c}-0.049 * * * \\
(0.011)\end{array}$ \\
\hline$\Delta y_{t}^{i, j}$ & & & $\begin{array}{c}0.157^{* * *} \\
(0.007)\end{array}$ & $\begin{array}{c}0.153^{* * * *} \\
(0.007)\end{array}$ \\
\hline$\Delta y_{t}^{i, j} * \operatorname{border}_{i, j}$ & & & $\begin{array}{l}-0.013 \\
(0.011)\end{array}$ & $\begin{array}{l}-0.013 \\
(0.014)\end{array}$ \\
\hline$\Delta y_{t}^{i, j} * \ln \tilde{d}_{i, j}$ & & & $\begin{array}{l}-0.007 \\
(0.008)\end{array}$ & $\begin{array}{l}-0.005 \\
(0.010)\end{array}$ \\
\hline$\Delta e_{t}^{j, i}+\Delta e_{t}^{j, i} *$ border $_{i, j}$ & $\begin{array}{c}-0.023^{* * *} \\
(0.007)\end{array}$ & $\begin{array}{c}-0.023^{* * *} \\
(0.007)\end{array}$ & $\begin{array}{c}-0.029^{* * *} \\
(0.007)\end{array}$ & $\begin{array}{c}-0.028^{* * *} * \\
(0.007)\end{array}$ \\
\hline$N$ & 56324 & 56324 & 56324 & 56324 \\
\hline$R^{2}$ & 0.01 & 0.0074 & 0.0262 & 0.0261 \\
\hline \multicolumn{5}{|c|}{$\begin{array}{l}\text { Notes: The dependent variable is relative consumption growth between locations } i \text { and } j, \Delta c_{t}^{i, j} \text {. The esti- } \\
\text { mated specification in columns (i)-(ii) is equation (2.3); while in columns (iii)-(iv) it is equation }(2.4) \text {. Robust } \\
\text { standard errors are in parentheses. }{ }^{*}, * * \text {, and }{ }^{* * *} \text { indicate significance at } 10 \%, 5 \% \text {, and } 1 \% \text {, respectively. }\end{array}$} \\
\hline
\end{tabular}

Our findings from the OLS and fixed effects estimation of equation (2.3) are presented in columns (i) and (ii) of Table $2 .{ }^{7}$ The results in column (i) indicate that the conditional correlation between the growth rates of RER and relative consumption within US and Canada is positive and significant, equal to 0.43 on average. We can also see that the estimated border effect is large and economically significant. In fact, due to this effect, the consumption-RER correlation across countries turns negative, equal to -0.023 on average. Taking (2.2) as our basic theory of risk-sharing, these results suggest that relative prices facilitate risk-sharing within countries, but

\footnotetext{
${ }^{6}$ We measure distance in kilometers.

${ }^{7}$ In the fixed effects regression the fixed effects capture the time-invariant, bilateral pair specific effects.
} 
impede risk-sharing across countries. The estimates in column (ii) obtained from the fixed effects regression confirm this finding. ${ }^{8}$

How sensitive are these findings to the assumption of complete access to capital markets? Many studies of risk-sharing, both intra-national and international, have relaxed this assumption and posited the alternative specification in which at least a fraction of consumers do not make consumption plans based on intertemporal optimization, but rather follow rules of thumb, or equivalently, have no ability to borrow and lend at all. ${ }^{9}$ To allow for this, we extend our framework to encompass limited capital market participation. Say that a fraction of households are hand-to-mouth consumers; that is they are restricted to consume only their current income. These households do not have access to capital markets, and therefore cannot participate in international risk-sharing. The testable implication of such a modified model is that relative consumption growth of these hand-to-mouth consumers living in any two locations follows their relative income growth. Let $\Delta y_{t}^{i, j}=\Delta \ln Y_{i, t}-\Delta \ln Y_{j, t}$ denote the relative income growth between locations $i$ and $j$ at time $t$. Then the relationship in (2.3) must be modified to account for the limited participation as follows:

$$
\begin{aligned}
\Delta c_{t}^{i, j} & =\beta_{0}+\beta_{1} \Delta e_{t}^{j, i}+\beta_{2}\left(\Delta e_{t}^{j, i} * \operatorname{border}_{i, j}\right)+\beta_{3} \Delta e_{t}^{j, i} * \ln \tilde{d}_{i, j} \\
& +\beta_{4} \Delta y_{t}^{i, j}+\beta_{5}\left(\Delta y_{t}^{i, j} * \operatorname{border}_{i, j}\right)+\beta_{6} \Delta y_{t}^{i, j} * \ln \tilde{d}_{i, j}+v_{t}^{i, j}
\end{aligned}
$$

Note that the equation specification in (2.4) allows for the border effect in the consumption-income relationship, and for the interaction term between $\Delta y_{t}^{i, j}$ and the normalized distance measure to allow the relationship between $\Delta c_{t}^{i, j}$ and $\Delta y_{t}^{i, j}$ to change monotonically with the distance. The results from this estimation are presented in columns (iii) and (iv) of Table 2. We find that there is significant positive association between $\Delta c_{t}^{i, j}$ and $\Delta y_{t}^{i, j}$ in both pooled and fixed effects specifications. Allowing for limited participation also affects the within-country correlation between $\Delta c_{t}^{i, j}$ and $\Delta e_{t}^{j, i}$ as it declines to about 0.32 . At the same time, the border effect in the consumptionreal exchange rate relationship remains negative and significant. In fact, this effect turns the correlation between $\Delta c_{t}^{i, j}$ and $\Delta e_{t}^{j, i}$ for the UC pairs negative and significant, as before. Overall, our estimated border effect in the consumption-real exchange rate risk-sharing remains robust to the inclusion of income.

\subsubsection{What drives the border effect?}

We now investigate the source of the negative border effect. That is, what explains the negative relationship between consumption and the real exchange rate across borders? For this purpose we decompose the real exchange rate into its components as follows. Recall the definition of the real

\footnotetext{
${ }^{8}$ Note that the coefficient on the interactive term between RER and log distance indicates that the consumptionRER correlation declines for the jurisdictions that are located further away from each other.

${ }^{9}$ See for instance, Crucini (1999), Hess and Shin (2000), Hess and Shin (2010), Kollmann (2009a) and Devereux, Smith, and Yetman (2009).
} 
exchange rate: $R E R_{t}^{j, i}=P_{j, t} S_{t}^{i, j} / P_{i, t}$. Taking logs and first-differencing we get

$$
\Delta \ln R E R_{t}^{j, i}=\Delta \ln \left(P_{j, t} / P_{i, t}\right)+\Delta \ln S_{t}^{i, j}
$$

where the first term on the right-hand-side captures movements in the the real exchange rate due to changes in the relative prices, while the second term is due to the movements in the nominal exchange rate. Table 3 reports the summary statistics for the three terms above.

Table 3: Decomposing RER movements for UC location pairs

\begin{tabular}{lccccc}
\hline \hline Variable & $\begin{array}{c}\text { Obs } \\
(\mathrm{i})\end{array}$ & $\begin{array}{c}\text { Mean } \\
(\mathrm{ii})\end{array}$ & $\begin{array}{c}\text { Std. Dev. } \\
(\mathrm{iii})\end{array}$ & $\begin{array}{c}\text { Min } \\
(\mathrm{iv})\end{array}$ & $\begin{array}{c}\text { Max } \\
(\mathrm{v})\end{array}$ \\
\hline$\Delta \ln R E R_{t}^{j, i}$ & 13000 & 0.0009 & 0.0551 & -0.1604 & 0.1588 \\
$\Delta \ln \left(P_{j, t} / P_{i, t}\right)$ & 13000 & 0.0007 & 0.0177 & -0.0909 & 0.0910 \\
$\Delta \ln S_{t}^{i, j}$ & 13000 & 0.0002 & 0.0512 & -0.1134 & 0.0690 \\
\hline Notes: The table reports summary statistics of the presented variables for a \\
sample of all US-Canada pairs. Obs. refer to the number of observations in \\
each sample; Mean - sample average; Std. Dev. - sample standard deviation; \\
Min-sample minimum; Max-sample maximum.
\end{tabular}

As can be seen from column (iii) the real exchange rate across borders is very volatile and the majority of this volatility comes from nominal exchange rate movements. At the same time, relative prices across countries exhibit more volatility than their intra-national counterparts reported in Table 1: compare the volatility of $1.77 \%$ for UC location pairs with $1.17 \%$ for UU location pairs and $0.95 \%$ for CC location pairs. Next we amend our specification in equations (2.3) and (2.4) to include the growth rate in nominal exchange rates. This allows us to assess the relative contribution of real exchange rate components - relative prices and nominal exchange rate - to the consumptionreal exchange rate relationship. The results are presented in Table 4.

Columns (i) and (ii) provide estimates of specification (2.3), while columns (iii) and (iv) allow for market segmentation and thus summarize the estimates of specification (2.4), both amended to include the nominal exchange rate growth rate between regions $i$ and $j$. The key result that stands out from Table 4 is that border effect turns positive when we control for nominal exchange rate movements. The coefficient on the nominal exchange rate growth, in turn, is negative and significant. This suggests that the negative border effect estimated in Table 2 is primarily due to the nominal exchange rate movements. This supports the findings of Hess and Shin (2010) and Hadzi-Vaskov (2008) who look at cross country regressions in which different bilateral pairs of countries have differences in their exchange rate volatility. Thus, without at this stage suggesting causation, the finding seems to indicate that country pairs with higher nominal exchange rate volatility will deviate more from the benchmark model of full risk sharing.

To sum up so far, our findings seem to suggest that the relative price movements facilitate consumption risk-sharing across Canadian provinces, and across the U.S. states; while they obstruct consumption risk-sharing across the Canada-US border. Moreover, most of this border effect can be attributed to nominal exchange rate variability. 
Table 4: Estimates of the Border Effect: RER Decomposition

\begin{tabular}{|c|c|c|c|c|}
\hline & $\begin{array}{l}\text { Pooled } \\
\text { (i) }\end{array}$ & $\begin{array}{l}\text { Fixed effects } \\
\text { (ii) }\end{array}$ & $\begin{array}{l}\text { Pooled } \\
\text { (iii) }\end{array}$ & $\begin{array}{l}\text { Fixed effects } \\
\text { (iv) }\end{array}$ \\
\hline$\Delta e_{t}^{j, i}$ & $\begin{array}{c}0.429^{* * *} \\
(0.023)\end{array}$ & $\begin{array}{c}0.424^{* * *} \\
(0.026)\end{array}$ & $\begin{array}{c}0.320^{* * *} \\
(0.023)\end{array}$ & $\begin{array}{c}0.318^{* * *} \\
(0.027)\end{array}$ \\
\hline$\Delta e_{t}^{j, i} * \operatorname{border}_{i, j}$ & $\begin{array}{c}0.033 \\
(0.031)\end{array}$ & $\begin{array}{l}0.043 \\
(0.035)\end{array}$ & $\begin{array}{c}0.114^{* * *} \\
(0.030)\end{array}$ & $\begin{array}{c}0.125^{* * *} \\
(0.034)\end{array}$ \\
\hline$\Delta e_{t}^{j, i} * \ln \tilde{d}_{i, j}$ & $\begin{array}{c}-0.056^{* * *} \\
(0.011)\end{array}$ & $\begin{array}{c}-0.057^{* * *} \\
(0.012)\end{array}$ & $\begin{array}{c}-0.050^{* * *} \\
(0.011)\end{array}$ & $\begin{array}{c}-0.051^{* * *} \\
(0.011)\end{array}$ \\
\hline$\Delta y_{t}^{i, j}$ & & & $\begin{array}{c}0.156^{* * *} \\
(0.007)\end{array}$ & $\begin{array}{c}0.152^{* * * *} \\
(0.007)\end{array}$ \\
\hline$\Delta y_{t}^{i, j} *$ border $_{i, j}$ & & & $\begin{array}{c}-0.024^{* * *} \\
(0.010)\end{array}$ & $\begin{array}{r}-0.024^{*} \\
(0.013)\end{array}$ \\
\hline$\Delta y_{t}^{i, j} * \ln \tilde{d}_{i, j}$ & & & $\begin{array}{l}-0.005 \\
(0.007)\end{array}$ & $\begin{array}{l}-0.002 \\
(0.009)\end{array}$ \\
\hline$\Delta \ln S_{t}^{i, j}$ & $\begin{array}{c}-0.551^{* * *} \\
(0.021)\end{array}$ & $\begin{array}{c}-0.555^{* * *} \\
(0.024) \\
\end{array}$ & $\begin{array}{c}-0.525^{* * *} \\
(0.021)\end{array}$ & $\begin{array}{c}-0.532^{* * *} \\
(0.022) \\
\end{array}$ \\
\hline $\begin{array}{l}N \\
R^{2}\end{array}$ & 56324 & 56324 & 56324 & 56324 \\
\hline $\begin{array}{l}\text { Notes: The depe } \\
\text { timated specifica } \\
\text { Both are modifie } \\
\text { parentheses. } * * *\end{array}$ & $\begin{array}{l}\text { ent varia } \\
\mathrm{n} \text { in colu } \\
\text { o include }\end{array}$ & $\begin{array}{l}\text { relative con } \\
\text { (i)-(ii) is equ } \\
\text { growth rate }\end{array}$ & $\begin{array}{l}\text { option } \mathrm{gr} \\
\text { on }(2.3) \text {; } \\
\text { he nomin }\end{array}$ & $\begin{array}{l}\text { tions } i \text { and } j, \Delta c_{t}^{i, j} \text {. The es- } \\
\text { (iii)-(iv) it is equation }(2.4) \text {. } \\
\text { Robust standard errors are in } \\
\text { vely. }\end{array}$ \\
\hline
\end{tabular}

\subsection{Robustness}

\subsubsection{Extended sample}

We next expand our sample of countries to include Japanese prefectures, Spanish communities and German bundeslaender. Our data for Germany covers 16 bundeslaender over 1995-2007 period; for Japan our dataset covers 47 prefectures over 1990-2005 period; while for Spain we have data for 18 autonomous communities over 1995-2004 period. For each country our dataset includes information on consumption, price indices and output in each regional unit. Summary statistics for the extended sample are presented in Table 5.

As before, we report the mean, standard deviation, minimum and maximum for the key variables of interest. These statistics are reported for the within-country pairs in Germany (Panel 1), Spain (Panel 2), and Japan (Panel 3); as well as for all cross-country pairs between Canada, US, Germany, Spain and Japan (Panel 4). Panel 4 also includes summary statistics on the components of the RER growth rate as shown in equation (2.5). The numbers tell a story similar to that for the US and Canada: International RER are significantly more volatile than RER for within-country pairs and are more volatile than international consumption differentials. Within-country RER are much smoother and in fact are less volatile than relative consumption within our group of countries. Furthermore, as evident from Panel 4, majority of cross-border RER fluctuations is due to movements in the nominal exchange rate. Next, we turn to the regression analysis.

Table 6 presents our estimates of the border effect for the five countries comprising our full sample. Columns (i) and (ii) report our estimates of equations (2.3), while columns (iii) and (iv) report the estimates for equation (2.4). 
Table 5: Sample summary statistics, extended sample

\begin{tabular}{|c|c|c|c|c|c|}
\hline Variable & $\begin{array}{l}\text { Obs } \\
\text { (i) }\end{array}$ & $\begin{array}{l}\text { Mean } \\
\text { (ii) }\end{array}$ & $\begin{array}{l}\text { Std. Dev. } \\
\text { (iii) }\end{array}$ & $\begin{array}{l}\text { Min } \\
\text { (iv) }\end{array}$ & $\begin{array}{c}\text { Max } \\
(\mathrm{v})\end{array}$ \\
\hline \multicolumn{6}{|l|}{ Panel 1: Germany } \\
\hline$\Delta \ln C_{i, t}-\Delta \ln C_{j, t}$ & 2040 & 0.0039 & 0.0183 & -0.0515 & 0.0793 \\
\hline$\Delta \ln Y_{i, t}-\Delta \ln Y_{j, t}$ & 2040 & 0.0079 & 0.0410 & -0.1696 & 0.1955 \\
\hline$\Delta \ln R E R_{t}^{j, i}$ & 2040 & -0.0019 & 0.0182 & -0.0890 & 0.0886 \\
\hline \multicolumn{6}{|l|}{ Panel 2: Spain } \\
\hline$\Delta \ln C_{i, t}-\Delta \ln C_{j, t}$ & 1377 & -0.0035 & 0.0145 & -0.0661 & 0.0473 \\
\hline$\Delta \ln Y_{i, t}-\Delta \ln Y_{j, t}$ & 1377 & -0.0007 & 0.1364 & -0.6737 & 0.6718 \\
\hline$\Delta \ln R E R_{t}^{j, i}$ & 1377 & -0.0014 & 0.0046 & -0.0171 & 0.0131 \\
\hline \multicolumn{6}{|l|}{ Panel 3: Japan } \\
\hline$\Delta \ln C_{i, t}-\Delta \ln C_{j, t}$ & 16215 & 0.0002 & 0.0251 & -0.1310 & 0.1614 \\
\hline$\Delta \ln Y_{i, t}-\Delta \ln Y_{j, t}$ & 16215 & 0.0003 & 0.0224 & -0.0946 & 0.1033 \\
\hline$\Delta \ln R E R_{t}^{j, i}$ & 16215 & -0.0002 & 0.0090 & -0.0645 & 0.0713 \\
\hline $\begin{array}{l}\text { Panel 4: All cross } \\
\Delta \ln C_{i, t}-\Delta \ln C_{j, t}\end{array}$ & 93660 & -0.0031 & 0.0367 & -0.3250 & 0.3662 \\
\hline$\Delta \ln Y_{i, t}-\Delta \ln Y_{j, t}$ & 93660 & -0.0004 & 0.0602 & -0.7456 & 0.7908 \\
\hline$\Delta \ln R E R_{t}^{j, i}$ & 93660 & 0.0070 & 0.0933 & -0.2218 & 0.2272 \\
\hline$\Delta \ln \left(P_{j, t} / P_{i, t}\right)$ & 93660 & 0.0085 & 0.0264 & -0.1178 & 0.1270 \\
\hline$\Delta \ln S_{t}^{i, j}$ & 93660 & -0.0015 & 0.0896 & -0.2007 & 0.2007 \\
\hline \multicolumn{6}{|c|}{$\begin{array}{l}\text { Notes: The table reports summary statistics of the presented variables for several samples: all Germany bundeslaen- } \\
\text { der pairs (Panel 1); all Spain autonomous communities pairs (Panel 2); all Japan prefecture pairs (Panel 3); and all } \\
\text { cross-country pairs for the five countries in our extended sample (Panel 4). Obs. refer to the number of observations } \\
\text { in each sample; Mean - sample average; Std. Dev. - sample standard deviation; Min-sample minimum; Max-sample } \\
\text { maximum. }\end{array}$} \\
\hline
\end{tabular}

Consistent with our findings for the US and Canada, the intra-national consumption-real exchange rate correlation for our sample of countries is positive and significant, equal to about 0.35 in a benchmark specification, and to about 0.28 when we control for the effect of output on consumption. This correlation declines dramatically when we account for the border. In particular, the cross-country consumption-real exchange rate correlation is -0.02 when estimated from a pooled regression, and increases to -0.01 in the fixed effects specification (robust to the inclusion of output). Both correlations are highly significant. Table 7 confirms that the majority of this drop in the correlation is due to nominal exchange rate movements - the coefficient on the variable $\left(\Delta \ln S_{t}^{i, j}\right)$ is negative and significant. It is also worthwhile to note that the coefficient on the $\Delta e_{t}^{j, i} * b o r d e r_{i, j}$ variable is negative and significant, implying that the movements of cross-border relative prices (controlling for the nominal exchange rate) also reduce international risk-sharing in our full sample of countries.

Overall, our empirical analysis provides us with several insights into the consumption-RER relationship: (i) Within countries this correlation is positive and significant, implying some amount of intra-national risk-sharing. This risk-sharing, however, is far from perfect; (ii) Across countries, the consumption-real exchange rate correlation is significantly smaller than within countries. It is in fact negative between US and Canada, and in the full sample of countries; (iii) The majority of the decline in international risk-sharing relative to the intra-national risk-sharing is due to nominal exchange rate co-moving negatively with relative consumption; (iv) International relative price movements (controlling for nominal exchange rate changes) hinder international risk-sharing. 
Table 6: Estimates of Border Effect, all countries

\begin{tabular}{|c|c|c|c|c|}
\hline & $\begin{array}{l}\text { Pooled } \\
\text { (i) }\end{array}$ & $\begin{array}{l}\text { Fixed effects } \\
\text { (ii) }\end{array}$ & $\begin{array}{l}\text { Pooled } \\
\text { (iii) }\end{array}$ & $\begin{array}{c}\text { Fixed effects } \\
\text { (iv) }\end{array}$ \\
\hline$\Delta e_{t}^{j, i}$ & $\begin{array}{c}0.349^{* * *} \\
(0.019)\end{array}$ & $\begin{array}{c}0.373^{* * *} \\
(0.023)\end{array}$ & $\begin{array}{c}0.275^{* * *} \\
(0.019)\end{array}$ & $\begin{array}{c}0.298^{* * *} \\
(0.022)\end{array}$ \\
\hline$\Delta e_{t}^{j, i} * \operatorname{border}_{i, j}$ & $\begin{array}{c}-0.371^{* * *} \\
(0.020)\end{array}$ & $\begin{array}{c}-0.385^{* * *} \\
(0.024)\end{array}$ & $\begin{array}{c}-0.291^{* * * *} \\
(0.020)\end{array}$ & $\begin{array}{c}-0.305^{* * *} \\
(0.023)\end{array}$ \\
\hline$\Delta e_{t}^{j, i} * \ln \tilde{d}_{i, j}$ & $\begin{array}{c}0.021^{* * *} \\
(0.003)\end{array}$ & $\begin{array}{c}0.026^{* * *} \\
(0.004)\end{array}$ & $\begin{array}{c}0.019^{* * *} \\
(0.003)\end{array}$ & $\begin{array}{c}0.022^{* * *} \\
(0.004)\end{array}$ \\
\hline$\Delta y_{t}^{i, j}$ & & & $\begin{array}{c}0.169^{* * * *} \\
(0.006)\end{array}$ & $\begin{array}{c}0.161^{* * *} \\
(0.008)\end{array}$ \\
\hline$\Delta y_{t}^{i, j} *$ border $_{i, j}$ & & & $\begin{array}{c}-0.036^{* * *} \\
(0.008)\end{array}$ & $\begin{array}{c}-0.050^{* * * *} \\
(0.012)\end{array}$ \\
\hline$\Delta y_{t}^{i, j} * \ln \tilde{d}_{i, j}$ & & & $\begin{array}{c}0.040^{* * *} \\
(0.004)\end{array}$ & $\begin{array}{c}0.039^{* * *} \\
(0.005)\end{array}$ \\
\hline$\Delta e_{t}^{j, i}+\Delta e_{t}^{j, i} *$ border $_{i, j}$ & $\begin{array}{c}-0.022^{* * *} \\
(0.004)\end{array}$ & $\begin{array}{c}-0.012^{* * *} \\
(0.004)\end{array}$ & $\begin{array}{c}-0.016^{* * *} \\
(0.004)\end{array}$ & $\begin{array}{c}-0.008^{* *} \\
(0.004) \\
\end{array}$ \\
\hline$N$ & 156509 & 156509 & 156509 & 156509 \\
\hline$R^{2}$ & 0.003 & 0.003 & 0.050 & 0.047 \\
\hline \multicolumn{5}{|c|}{$\begin{array}{l}\text { Notes: The dependent variable is relative consumption growth between locations } i \text { and } j, \Delta c_{t}^{i, j} \text {. The esti- } \\
\text { mated specification in columns (i)-(ii) is equation }(2.3) \text {; while in columns (iii)-(iv) it is equation }(2.4) \text {. Robust } \\
\text { standard errors are in parentheses. } *, * * \text {, and } * * * \text { indicate significance at } 10 \%, 5 \% \text {, and } 1 \% \text {, respectively. }\end{array}$} \\
\hline
\end{tabular}

\subsubsection{Country heterogeneity}

In the regression specifications (2.3) and (2.4) the effect of the border on C-RER correlation, as captured by the interactive term on the RER with the border dummy, is measured relative to the average C-RER correlation in the intra-country pairs. Gorodnichenko and Tesar (2009) argue that in the presence of cross-country heterogeneity in the distribution of within-country price differentials and consumption differentials, such benchmark is arbitrary and can lead to misleading results. In particular, in this case, the border coefficient may capture the joint effect of the border and cross-country heterogeneity in C-RER correlation.

We next address this issue by allowing the intra-national correlation between $\Delta c_{t}^{i, j}$ and $\Delta e_{t}^{j, i}$ to be country-specific. In particular, we amend the regression specification in equation (2.4) with the product terms of $\Delta e_{t}^{j, i}$ with a set of dummy variables, each identifying within-country jurisdiction pairs in each country in our sample. In all cases we use within US state pairs as the benchmark.

For instance, for US-Canada case, we include in the regression (2.4) an interactive term of $\Delta e_{t}^{j, i}$ with a dummy variable that equals one for all province pairs within Canada. The coefficient on this interactive term will give us the change in the intra-national C-RER when transitioning from US state pairs to Canadian province pairs. The coefficient on the interactive term between $\Delta e_{t}^{j, i}$ and border dummy, as before, will give us the effect of the border on C-RER correlation, except now we can estimate the effect of the border crossing from the perspective of each individual country in our sample.

Table 8 reports our results for the US-Canada sample and for the extended sample of 5 countries. ${ }^{10}$ For completeness, panel (a) summarizes our earlier results from the fixed effects regressions

\footnotetext{
${ }^{10}$ Detailed estimation results are available from the authors upon request.
} 
Table 7: Estimates of the Border Effect: RER Decomposition, all countries

\begin{tabular}{|c|c|c|}
\hline & $\begin{array}{l}\text { Fixed effects } \\
\text { (i) }\end{array}$ & $\begin{array}{l}\text { Fixed effects } \\
\text { (ii) }\end{array}$ \\
\hline$\Delta e_{t}^{j, i}$ & $\begin{array}{c}0.384^{* * *} \\
(0.023)\end{array}$ & $\begin{array}{c}0.308^{* * *} \\
(0.022)\end{array}$ \\
\hline$\Delta e_{t}^{j, i} * b o r d e r_{i, j}$ & $\begin{array}{c}-0.127^{* * *} \\
(0.026)\end{array}$ & $\begin{array}{c}-0.061^{* * *} \\
(0.025)\end{array}$ \\
\hline$\Delta e_{t}^{j, i} * \ln \tilde{d}_{i, j}$ & $\begin{array}{c}0.038^{* * *} \\
(0.004)\end{array}$ & $\begin{array}{c}0.034^{* * *} \\
(0.004)\end{array}$ \\
\hline$\Delta y_{t}^{i, j}$ & & $\begin{array}{c}0.159^{* * * *} \\
(0.008)\end{array}$ \\
\hline$\Delta y_{t}^{i, j} *$ border $_{i, j}$ & & $\begin{array}{c}-0.049^{* * *} \\
(0.012)\end{array}$ \\
\hline$\Delta y_{t}^{i, j} * \ln \tilde{d}_{i, j}$ & & $\begin{array}{c}0.037 * * * \\
(0.005)\end{array}$ \\
\hline$\Delta \ln S_{t}^{i, j}$ & $\begin{array}{c}-0.293^{* * *} \\
(0.011)\end{array}$ & $\begin{array}{c}-0.278^{* * *} \\
(0.010)\end{array}$ \\
\hline$N$ & 156509 & 156509 \\
\hline$R^{2}$ & 0.001 & 0.022 \\
\hline \multicolumn{3}{|c|}{$\begin{array}{l}\text { Notes: The dependent variable is relative consumption growth between locations } \\
\text { and } j, \Delta c_{t}^{i, j} \text {. The estimated specification in column (i) is equation }(2.3) \text {, while in } \\
\text { column (ii) is equation }(2.4) \text {. Both are modified to include the growth rate of the } \\
\text { nominal exchange rate. Robust standard errors are in parentheses. } *, * * \text {, and } \\
\text { indicate significance at } 10 \%, 5 \% \text {, and } 1 \% \text {, respectively. }\end{array}$} \\
\hline
\end{tabular}

where we used the average correlation in the intra-country pairs as the benchmark for gauging the border effect (see columns (ii) and (iv) in Tables 2 and 6). Panel (b) presents the estimation results that allow for country heterogeneity. We report the results from the specification with handto-mouth consumers (columns labelled "with $\Delta y_{t}^{i, j}$ ") and with homogeneous consumers (columns labelled "no $\left.\Delta y_{t}^{i, j}{ }^{1}\right) .{ }^{11}$ All regressions include jurisdiction-pairs fixed effects.

Our results reveal some amount of heterogeneity across our sample of countries. However, some common patterns emerge. First, intra-national C-RER correlations are consistently positive, with the US and Spain showing the highest numbers in our sample, while Germany is characterized by the lowest correlation. ${ }^{12}$ Second, international correlations are negative for all countries, except Spain. The correlations are the lowest (most negative) in Germany.

\subsubsection{Exchange rate regime}

To further assess the role of the exchange rate in C-RER correlations, we turn to international evidence. In particular, we study a cohort of the 12 European Union member states during 1974-2007 period. ${ }^{13}$ To evaluate the role of the exchange rate, we split the sample into pre-euro period (19741998) and euro period (1999-2007). ${ }^{14}$ For each subsample we compute all bilateral correlations

\footnotetext{
${ }^{11}$ Specification with the hand-to-mouth consumers also includes the interactive terms between output growth and dummy variables that identify within-country jurisdiction pairs for each country in our sample. This allows the consumption-output growth correlations to be country-specific as well.

${ }^{12}$ The only exception is Germany in the specification with no hand-to-mouth consumers, who exhibits negative intra-national C-RER correlation.

${ }^{13}$ Data details and sources are provided in the Appendix A.1.

${ }^{14}$ Greece adopted euro on January 1, 2001. We adjust our calculations accordingly.
} 
Table 8: International C-RER correlation: Accounting for country heterogeneity

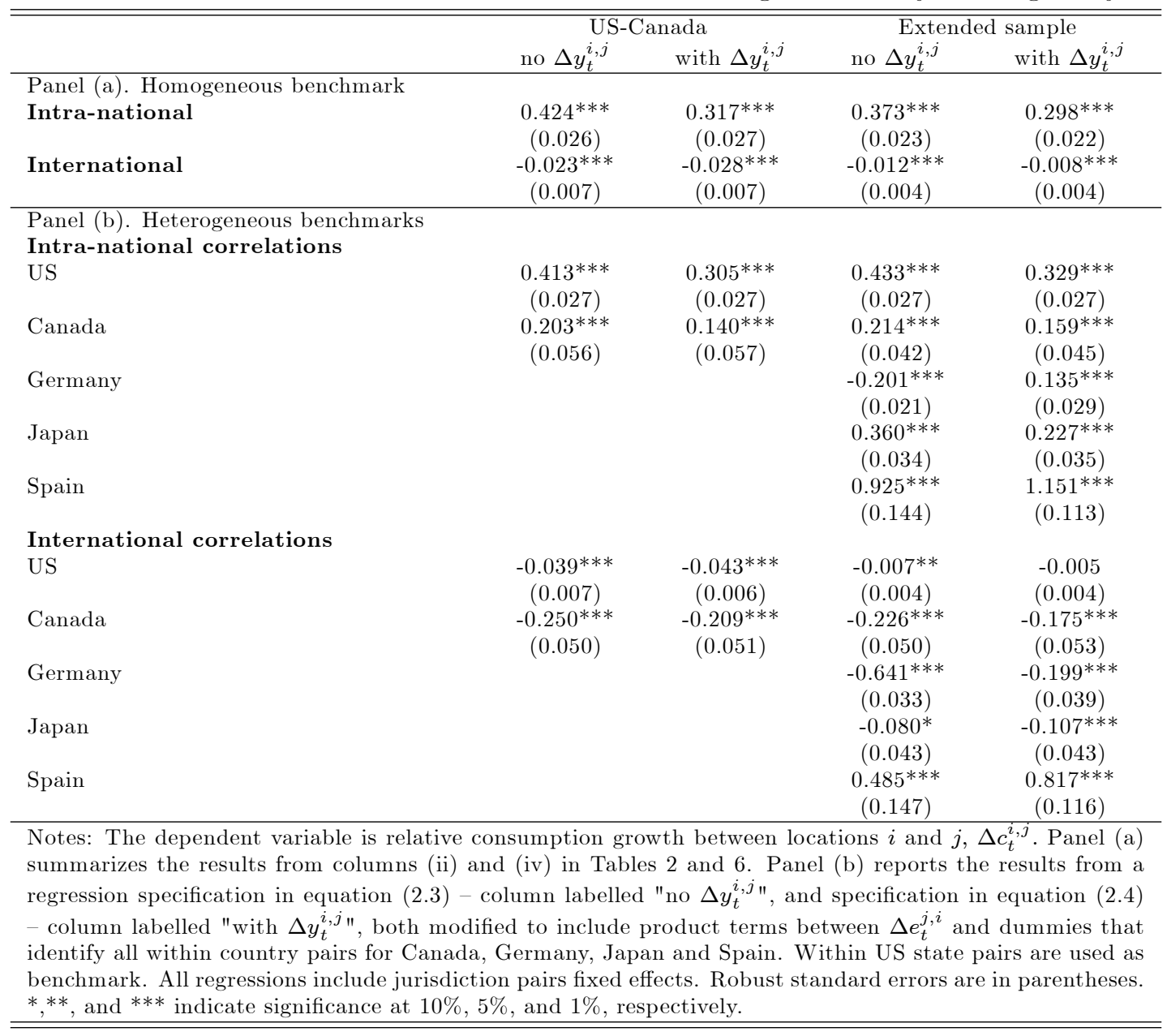

of relative consumption growth with the growth rate in the RER for each country. The average correlations for each country and each sub-period are reported in Table 9. A clear contrast arises between the two periods: In the pre-euro period, the C-RER correlation is negative, on average, across countries, equal to -0.12 . The same correlation turns positive in the euro period and is equal to 0.03 .

These results support our earlier findings on the role of exchange rate fluctuations for the finding of negative correlation between relative consumption growth and RER growth. ${ }^{15}$

\footnotetext{
${ }^{15}$ We recognize that besides the exchange rate regime, other factors could have also contributed to the increase in the C-RER correlation in the second sub-period. For instance, the degree of financial integration could have risen, or policy coordination could have increased in the latter period between the EU members. However, the evidence in this subsection, together with intra-national comparisons suggest to us that the exchange rate is an important part of the story.
} 
Table 9: International C-RER correlation: Fixed vs flexible regime

\begin{tabular}{lcc}
\hline \hline & $\begin{array}{c}\text { Pre-euro period } \\
1974-1998\end{array}$ & $\begin{array}{c}\text { Euro period } \\
\text { 1999-present } \\
(\mathrm{i})\end{array}$ \\
\hline Austria & -0.13 & 0.05 \\
Belgium & 0.05 & 0.10 \\
Finland & -0.43 & 0.28 \\
France & -0.07 & -0.03 \\
Germany & -0.07 & 0.19 \\
Greece & -0.08 & -0.16 \\
Ireland & 0.14 & -0.15 \\
Italy & -0.21 & -0.01 \\
Luxembourg & 0.02 & 0.25 \\
Netherlands & -0.16 & -0.29 \\
Portugal & -0.38 & 0.24 \\
Spain & -0.06 & -0.11 \\
\hline Average & -0.12 & 0.03 \\
\hline \hline
\end{tabular}

\subsection{An alternative measure of risk-sharing and the role of the nominal exchange rate}

Up to now, we have assumed that the benchmark for efficient risk-sharing in the data is that relative consumption growth rates across any two locations should be positively associated with the real exchange rate, independent of other variables. But these tests do not give a metric for the degree to which risk-sharing fails in the data, nor the extent to which the border (or the nominal exchange rate) contributes to this failure. Here we follow in the spirit of (Engel and Rogers (1996)) in constructing a measure of the degree to which the border accounts for the failure of risk-sharing. ${ }^{16}$ We return to equation (2.2) and for each regional pair, for a choice of $\sigma$, we compute $\Delta c_{t}^{i, j}-(1 / \sigma) \Delta e_{t}^{j, i}$ and obtain its standard deviation in the time-series. ${ }^{17}$ This gives us a cross-section of such standard deviations. If our choice of $\sigma$ is correct, then with full risk-sharing this statistic would be zero for each bilateral pair. ${ }^{18}$ The summary statistics of this measure are reported in panel (i) of Table 10.

Table 10: Alternative meaure of risk-sharing: Summary statistics

\begin{tabular}{|c|c|c|c|c|c|}
\hline Variable & $\overline{\mathrm{Obs}}$ & Mean & Std. Dev. & Min & Max \\
\hline (i) std.dev. $\left[\Delta c_{t}^{i, j}-(1 / \sigma) \Delta e_{t}^{j, i}\right]$ & 10146 & 0.0514 & 0.0183 & 0.0039 & 0.1391 \\
\hline (ii) std.dev. $\left[\Delta c_{t}^{i, j}-(1 / \sigma) \Delta \tilde{e}_{t}^{j, \vec{i}}\right]$ & 10146 & 0.0335 & 0.0156 & 0.0039 & 0.1107 \\
\hline
\end{tabular}

\footnotetext{
${ }^{16}$ Engel and Rogers (1996) measure the extent of the failure of the law of one price using the standard deviation of the price differentials of similar goods across cities in the US and Canada.

${ }^{17}$ We also conduct the analysis of this section using the mean of the squared difference, mean $\left[\Delta c_{t}^{i, j}-(1 / \sigma) \Delta \tilde{e}_{t}^{j, i}\right]^{2}$, and find that the results are robust to this alternative measure of risk-sharing.

${ }^{18}$ We set $\sigma=2$, so that the elasticity of intertemporal substitution is equal to 0.5 - a standard value in the literature.
} 
Using this measure of the departure from risk-sharing, we estimate the following regression:

$$
\text { std.dev. }\left[\Delta c_{t}^{i, j}-(1 / \sigma) \Delta e_{t}^{j, i}\right]=\beta_{1} \text { border }_{i, j}+\sum_{m=1}^{5} \alpha_{m} D_{m m}+\varepsilon_{i, j}
$$

where border $_{i, j}$, is as before a dummy variable that takes on a value of one if locations $i$ and $j$ are in separate countries, and zero otherwise, while $\varepsilon_{i, j}$ is the regression error term. We also consider a specification in which we include log of the distance between locations $i$ and $j$. To account for potential heterogeneity across countries in the average volatility of deviations from perfect risk-sharing, we also include a set of dummies, identifying within-country pairs, $D_{m m} \cdot{ }^{19}$ Table 11 reports the results. Panel (i) presents the results without the log distance variable in the specification, while panel (ii) - includes the log distance variable. The effect of the border is positive and significant. It means that controlling for country-specific volatility in risk-sharing measure, there is a greater deviation from efficient risk-sharing when comparing across countries relative to comparing within countries. This result holds whether we control for distance in our estimation or not. How important is the border? The average volatility of our risk-sharing measure is 5.14 percent, while the border coefficient is 2.74 percent, so the border accounts for 53 percent of the total, after controlling for distance.

Table 11: Alternative meaure of risk-sharing: The role of the border

\begin{tabular}{|c|c|c|c|c|c|}
\hline$\overline{\text { Variable }}$ & $\overline{\text { border }}$ & ln(distance) & $\overline{N N}$ & 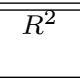 & $\begin{array}{l}\text { explained } \\
\text { by bordes }\end{array}$ \\
\hline (i) std.dev. $\left[\Delta c_{t}^{i, j}-(1 / \sigma) \Delta e_{t}^{j, i}\right]$ & $\begin{array}{c}0.0395^{* * *} \\
(0.0008)\end{array}$ & & 10146 & 0.44 & 0.77 \\
\hline (ii) std.dev. $\left[\Delta c_{t}^{i, j}-(1 / \sigma) \Delta e_{t}^{j, i}\right]$ & $\begin{array}{c}0.0274^{* * *} \\
(0.0009)\end{array}$ & $\begin{array}{c}0.0090^{* * *} \\
(0.0003)\end{array}$ & 10146 & 0.53 & 0.53 \\
\hline (iii) std.dev. $\left[\Delta c_{t}^{i, j}-(1 / \sigma) \Delta \tilde{e}_{t}^{j, i}\right]$ & $\begin{array}{c}0.0153^{* * *} \\
(0.0008)\end{array}$ & & 10146 & 0.29 & 0.46 \\
\hline (iv) std.dev. $\left[\Delta c_{t}^{i, j}-(1 / \sigma) \Delta \tilde{e}_{t}^{j, i}\right]$ & $\begin{array}{c}0.0116^{* * *} \\
(0.0008)\end{array}$ & $\begin{array}{c}0.0027^{* * *} \\
(0.0002)\end{array}$ & 10146 & 0.31 & 0.35 \\
\hline
\end{tabular}

Can this border effect be attributed to movements in the nominal exchange rate, as argued previously? In this example, the test is purely a cross-section one, so we cannot include the nominal exchange rate as a right-hand side variable. But we can again follow Engel and Rogers (1996) in using an alternative measure of real exchange rates as the relative real price. To control for the volatility of the nominal exchange we obtain a measure of the real exchange rate as the relative foreign to home real price, so that nominal exchange rate does not appear in the calculations.

Define $P_{i}^{*} / P^{*}$ to be the ratio of the price level in jurisdiction $i$ to the aggregate price in the foreign country. Similarly, let the home real price be defined as $P_{j} / P$, where $P$ is the aggregate

\footnotetext{
${ }^{19}$ Note that this is a cross-sectional regression.
} 
price index at home. Then the relative real price between locations $i$ and $j$ is given by

$$
\widetilde{R E R}_{t}^{j, i}=\left(P_{j, t}^{*} / P_{t}^{*}\right) /\left(P_{i, t} / P_{t}\right)
$$

Note that for any two locations within the same country, $\widetilde{R E R}_{t}^{j, i}=P_{j, t} / P_{i, t}$ as before. But for any two locations in different countries, this alternative measure of the real exchange rate does not contain the nominal exchange rate. Engel and Rogers (1996) used this measure of the real exchange rate to test the degree to which the border effect could be attributed to nominal price stickiness, since if all nominal prices within countries were fixed and real exchange rates were fully accounted for by nominal exchange rate variation, then this measure of the real exchange rate would be constant, and the border effect would be insignificant. In the same spirit, this alternative real exchange rate definition gives us a way in which to assess the degree to which the presence of the nominal exchange rate accounts for the size of the border in deviations from efficient risk-sharing.

After computing $\widetilde{R E R}^{j, i}$, we repeat the steps above to construct the volatility of our risk-sharing measure for every jurisdiction pair as std.dev. $\left[\Delta c_{t}^{i, j}-(1 / \sigma) \Delta \tilde{e}_{t}^{j, i}\right]$, where $\Delta \tilde{e}_{t}^{j, i}=\ln \left(\widetilde{R E R}_{t}^{j, i}\right)-$ $\ln \left(\widetilde{R E R}_{t-1}^{j, i}\right)$. Panel (ii) of Table 10 presents the summary statistics on this adjusted measure. Clearly, this measure is less volatile than the original measure based on unadjusted real exchange rate. ${ }^{20}$ We then estimate the regression specification in (2.6) using this adjusted measure of deviations from the perfect risk-sharing. The results are reported in panels (iii) and (iv) of Table 11. We find that the coefficient on the border dummy is still positive and significant. But it is substantially smaller than before. How much does the border matter after we control for the nominal exchange rate in the calculation of relative prices? From panel (iv), the coefficient on the border dummy is 1.16 percent, while the average volatility of the adjusted risk-sharing measure as reported in Table 10 is 3.35 percent. So the border accounts for 35 percent of the standard deviation. Thus, when the nominal exchange rate is dropped from the calculation of the relative prices, the contribution of the border to the average volatility of the risk-sharing measure declines from 53 percent to 35 percent.

We next develop a theoretical framework to shed some light on our empirical findings.

\section{Consumption Risk-Sharing with Sticky Prices}

From the previous section, it is apparent that the presence of the nominal exchange rate plays a key role in empirical tests of the risk sharing relationship between bilateral consumption differences and real exchange rate changes. What can account for this? One obvious suggestion is that goods prices are sticky, and so substantial real exchange rate adjustment, in the short run, can be

\footnotetext{
${ }^{20}$ Engel (1999) shows that if preferences are identical across countries and the law of one price holds for traded goods, then the real exchange rate can be exactly written as a 'relative-relative' price, expressing the relative price of non-traded to traded goods for one country relative to the other country. If we substituted the price index for traded goods for the aggregate price index for each country, then our measure of the real exchange rate would be exact under the same conditions as Engel (1999).
} 
achieved only by nominal exchange rate movement. But while this may facilitate an explanation, it is not clearly a complete resolution of the problem. Many sticky price models (e.g. Clarida, Gali, and Gertler, 2002, Devereux and Engel, 2003) exhibit volatile real and nominal exchange rates, but still have the property that the cross country risk sharing condition between consumption and real exchange rates holds exactly. On the other hand, many models in the literature which offer potential resolutions to the Backus Smith puzzle have no role at all for the nominal exchange rate, and so cannot offer a robust explanation of the findings of the previous section in the sense that they imply that eliminating exchange rate volatility by fixing the exchange rate between two countries would have no implications for the empirical tests of risk-sharing.

In this section, we attempt to narrow this gap by combining features of the previous literature on the Backus Smith puzzle with a fairly standard two country 'New Keynesian' model with gradual price adjustment. We then ask whether this model exhibits the property that the sign of the CRER correlation depends upon the exchange rate regime. That is, we ask whether the apparent failure of efficient consumption risk sharing can be attributed to the presence of nominal exchange rate volatility?

As we show, the answer is nuanced, and requires a balance of a number of competing mechanisms. Ultimately, the question can be resolved down to the following requirement. We need to isolate a mechanism whereby, under a floating exchange rate system, the preponderance of shocks produces a negative correlation between relative consumption growth and the real exchange rate, with this negative correlation itself being accounted for by movements in the nominal exchange rate. At the same time it should be the case that under the same composition of shocks, a policy that fixes the nominal exchange rate changes the sign of the consumption growth and real exchange rate correlation to a positive number. As we show below, it is not the case that simply adding together the assumption of price stickiness with a menu of shocks that product a negative correlation can satisfy this joint desiderata.

To show this, we start with a 'bare-bones model' which has both; a) nominal prices stickiness, and b) a shock which can produce a negative correlation between consumption growth and the real exchange rate. In this simple model, we show that the introduction an exchange rate peg which eliminates nominal exchange rate flexibility cannot resolve the puzzle in the sense that it cannot reverse the sign of the C-RER correlation. We then introduce an additional mechanism that does help to achieve this sign reversal. Following this, we develop a more elaborate model, more closely related to the literature, identifying the key requirements that are necessary to reconcile the model with the empirical findings.

\subsection{A bare-bones model}

To see that sticky prices alone cannot explain the importance of the nominal exchange rate, we take the simplest possible New Keynesian open economy model; basically an extension of the Clarida, Gali, and Gertler (2002) framework. There are two countries, home and foreign. Let the utility of a representative infinitely lived home household evaluated from date 0 be defined as: 


$$
U_{t}=E_{0} \sum_{t=0}^{\infty}(\beta)^{t} \xi_{t}\left(\frac{C_{t}^{1-\sigma}}{1-\sigma}-\frac{N_{t}^{1+\phi}}{1+\phi}\right), \quad \beta<1 .
$$

where $C_{t}$ is the composite home consumption bundle, and $N_{t}$ is home labour supply. The variable $\xi_{t}$ represents a preference, or 'demand' shock, changing the intertemporal relative valuation of period by period utilities. $^{21}$ Composite consumption is defined as $C_{t}=\Phi C_{H t}^{v / 2} C_{F t}^{1-v / 2}, \quad v \geq 1$, indicating the possibility for home bias in preferences. ${ }^{22} \quad C_{H t}$ is the consumption of the home country composite good, while $C_{F t}$ is consumption of the foreign composite good by the home household. $C_{H t}$ and $C_{F t}$ are defined over the range of home and foreign differentiated goods with elasticity of substitution $\theta$ between goods. The aggregate (CPI) price index for the home country is $P=P_{H}^{\frac{v}{2}} P_{F}^{1-\frac{v}{2}}$. Demand for individual differentiated home and foreign goods and home and foreign composite goods may be obtained from these functions in the usual way. Each firm faces a demand elasticity of $\theta$.

In this example, we make the assumption of a complete set of state contingent international assets markets which implies that state-contingent nominal marginal utility is equated across countries, so that:

$$
\xi_{t} C_{t}^{-\sigma}=\xi_{t}^{*} C_{t}^{*-\sigma} \frac{S_{t} P_{t}^{*}}{P_{t}}=\xi_{t}^{*} C_{t}^{*-\sigma} T_{t}^{v-1}
$$

where $S_{t}$ is the nominal exchange rate (home price of foreign currency), $P_{t}^{*}=P_{F}^{* v / 2} P_{H}^{* 1-v / 2}$ is the foreign $C P I$, and $T=\frac{S P_{F}^{*}}{P_{H}}$ is the home country terms of trade. Thus, the real exchange rate becomes $T_{t}^{v-1}$. Implicit in this condition is the assumption that the law of one price holds, so that $P_{F}=S P_{F}^{*}$ and equivalently for home goods.

Note that in this simple example model, the only way in which there can arise a negative correlation between relative consumption and the real exchange rate is due to the presence of country-specific preference shocks $\xi_{t}$ and $\xi_{t}^{*}$. In the extended model below, we depart from this specification, explicitly allowing for incomplete financial markets, so that even in the absence of preference shocks, there may arise a negative correlation between realized relative consumption differences and the real exchange rate.

We assume that households also have access to a market in domestic nominal government bonds, each of which pays an interest rate of $R_{t}$ in all states of the world. Thus we can define an Euler equation for nominal bond pricing given by:

$$
\frac{\xi_{t} C_{t}^{-\sigma}}{P_{t}}=R_{t+1} E_{t} \beta \frac{\xi_{t+1} C_{t+1}^{-\sigma}}{P_{t+1}}
$$

Foreign households preferences and choices can be defined exactly symmetrically. The foreign representative household has weight $v / 2,(1-v / 2)$ on the foreign (home) composite good in preferences.

\footnotetext{
${ }^{21}$ See for instance, Stockman and Tesar (1995) for an early application of preference shocks in multi-country DSGE models.

${ }^{22}$ We define $\Phi=\left(\frac{v}{2}\right)^{\frac{v}{2}}\left(1-\left(\frac{v}{2}\right)\right)^{\frac{v}{2}}$.
} 
Assume that production technologies for all goods are linear in labour, so that for a home good $i$, we have production $Y(i)$ as:

$$
Y_{H t}(i)=A_{t} N_{t}(i)
$$

where $A_{t}$ is a common economy-wide productivity shock that applies to all home firms. Each home firm re-sets its price according to a Calvo pricing policy, where the probability of re-adjusting its price is $1-\kappa$ in each period. The optimal price for a typical firm $i$ in the home country is:

$$
\widetilde{P}_{H t}(i)=\frac{E_{t} \sum_{j=0} m_{t+j} \kappa^{j} \frac{W_{t+j}}{A_{t+j}} Y_{H t+j}(i)}{E_{t} \sum_{j=0} m_{t+j} \kappa^{j} Y_{H t+j}(i)} .
$$

where $m_{t}$ is a stochastic discount factor defined in the Appendix A.2, and $W_{t}$ is the nominal wage. ${ }^{23}$

In the aggregate, the price index for the home good then follows the process given by:

$$
P_{H t}=\left[(1-\kappa) \widetilde{P}_{H t}^{1-\theta}+\kappa P_{H t-1}^{1-\theta}\right]^{\frac{1}{1-\theta}} .
$$

The behavior of foreign firms and the foreign good price index may be described analogously.

Assume that the home country monetary authority follows a Taylor rule, which targets the inflation rate of the home good $\Pi_{H t}=\frac{P_{H t}}{P_{H t-1}}$, and the output gap of the home country $\frac{Y_{H t}}{\tilde{Y}_{H t}}$, where $Y_{H t}$ is home output (defined below), and $\tilde{Y}_{H t}$ is the flexible price (potential) level of home output. In addition, the monetary rule puts some weight on the nominal exchange rate. Specifically, the nominal interest rate $R_{t+1}$ is set so that:

$$
R_{t+1}=\beta^{-1}\left(\Pi_{H t}\right)^{\gamma_{\pi}}\left(\Pi_{S t}\right)^{\delta}\left(\frac{Y_{H t}}{\tilde{Y}_{H t}}\right)^{\gamma_{y}}
$$

Here we define $\Pi_{S t}=S_{t} / S_{t-1}$ as the gross rate of change of the nominal exchange rate. For very high values of $\delta>0$, the exchange rate will be effectively fixed. ${ }^{24}$ The main issue of interest here will be to contrast the behavior of consumption and real exchange rates for values of $\delta=0$, which we associate with a regime of inflation targeting in both countries, with a situation where the value of $\delta$ goes to a very high positive number.

The foreign monetary authority follows a Taylor rule, but does not directly target the exchange rate. $^{25}$

Market clearing conditions are given by:

$$
Y_{H t}=\frac{v}{2} \frac{P_{t}}{P_{H t}} C_{t}+\left(1-\frac{v}{2}\right) \frac{S_{t} P_{t}^{*}}{P_{H t}} C_{t}^{*}
$$

\footnotetext{
${ }^{23}$ We assume that there is an optimal subsidy in place that eliminates the distortionary effect of the price markup.

${ }^{24}$ Note that this specification is not associated with the problems of indeterminancy of a fixed exchange rate regime. The nominal exchange rate is fully determined, given an initial value $S_{0}$. See Benigno, Benigno, and Ghironi (2007).

${ }^{25}$ In fact, for the value of $\operatorname{corr}\left(\Delta\left(c-c^{*}\right), \Delta R E R\right)$, it is irrelevant which monetary authority targets the exchange rate, or whether it is done jointly. It is convenient to focus solely on home country exchange rate targeting, because this makes the analysis of nominal price adjustment more easy to exposit.
} 
Here $Y_{H t}=V_{t}^{-1} \int_{0}^{1} Y_{H t}(i) d i$ is aggregate home country output, where we have defined $V_{t}=\int_{0}^{1}\left(\frac{P_{H t}(i)}{P_{H t}}\right)^{-\theta} d i$. It follows that home country employment (employment for the representative individual home household) is given by $N_{t}=\int_{0}^{1} N(i) d i=A_{t}^{-1} Y_{H t} V_{t}$.

In the same manner, we may write the aggregate market clearing condition for the foreign good as

$$
Y_{F t}=\frac{v}{2} \frac{P_{t}^{*}}{P_{F t}^{*}} C_{t}^{*}+\left(1-\frac{v}{2}\right) \frac{P_{t}}{S_{t} P_{F t}^{*}} C_{t}^{*}
$$

The full solution of the model is defined in the Appendix A.2. Here we present the log linear approximation around an efficient, zero-inflation steady state. As usual in the open economy new Keynesian models, we may define an inflation equation as a forward looking relationship in home and foreign output rates. Let $x=\ln \left(X_{t} / \bar{X}\right)$ be the $\log$ deviation of any variable from its steady state (except for inflation and nominal interest rates, which are in levels).

We can use (3.8), (3.13) and (3.14) to solve for home and foreign consumption and the terms of trade as a function of aggregate home output. Then substituting into the linear approximation of (3.10) gives the inflation equation for the home country:

$$
\begin{aligned}
\pi_{H t}= & k\left((\phi+\omega(1+D)) y_{H t}+y_{F t} \omega(D-1)-\frac{\omega(D+v-1)}{\sigma} \varepsilon_{t}\right. \\
& \left.-\frac{\omega(D-v+1))}{\sigma} \varepsilon_{t}^{*}-(1+\phi) a_{t}\right)+\beta E_{t} \pi_{H t+1},
\end{aligned}
$$

where $k=\frac{(1-\beta \kappa)(1-\kappa)}{\kappa}, \omega=\frac{\sigma}{2 D}$, and $D=\sigma v(2-v)+(1-v)^{2}$.

Likewise, using (3.9) we may define the home country dynamic IS equation as:

$$
\begin{gathered}
E_{t}\left(y_{H t+1}-y_{H t}\right)(D+1)+E_{t}\left(y_{F t+1}^{*}-y_{F t}^{*}\right)(D-1)-\frac{(D+v-1)}{\sigma} E_{t}\left(\varepsilon_{t+1}-\varepsilon_{t}\right) \\
-\frac{(D-v+1)}{\sigma} E_{t}\left(\varepsilon_{t+1}^{*}-\varepsilon_{t}^{*}\right)=\omega^{-1} E_{t}\left(r_{t}-\pi_{H t+1}\right),
\end{gathered}
$$

where $r_{t}$ is the home country nominal interest rate, and the interest rate rule implies that: $r_{t}=$ $\gamma_{\pi} \pi_{H t}+\gamma_{y}\left(y_{t}-\widetilde{y}_{t}\right)+\delta\left(\tau_{t}-\tau_{t-1}\right)-\delta\left(\pi_{F t}-\pi_{H t}\right)$. An equivalent set of conditions hold for the foreign country, except we define the foreign interest rate rule as $r_{t}^{*}=\gamma_{\pi} \pi_{F t}+\gamma_{y}\left(y_{t}^{*}-\widetilde{y}_{t}^{*}\right)$. Here $\tau_{t}$ is the terms of trade in terms of log deviations. It may be shown that in this simple model, the terms of trade follows the process:

$$
\tau_{t}=-\frac{(v-1)}{D}\left(\varepsilon_{t}-\varepsilon_{t}^{*}\right)+\frac{\sigma\left(y_{H t}-y_{F t}\right)}{D}
$$

In addition, the linear approximation to (3.8) gives relative consumption as:

$$
c_{t}-c_{t}^{*}=\frac{1}{\sigma}\left(\varepsilon_{t}-\varepsilon_{t}^{*}\right)+\frac{(v-1)}{\sigma} \tau_{t}
$$

Equations (3.15) and (3.16), and the equivalent for the foreign country, along with the interest 
rate rules, and the terms of trade equation (3.17) may be solved for the path of inflation and output levels consequent on the shocks to preferences and technology.

First take the case with fully flexible exchange rates, so that $\delta=0$. We may then take the difference between (3.15) and its foreign counterpart, and (3.16) and its foreign counterpart, to express the two country model in terms of differentials in inflation and output levels, i.e. $\Delta \pi_{t}=$ $\pi_{H t}-\pi_{F t}^{*}$ and $\Delta y_{t}=y_{H t}-y_{F t}$ as follows:

$$
\begin{gathered}
\Delta \pi_{t}=k\left(\phi+\frac{\sigma}{D}\right) \Delta y_{t}-\frac{(v-1)}{D} \Delta \varepsilon_{t}-(1+\phi) \Delta a_{t}+\beta E_{t} \Delta \pi_{t+1} \\
\gamma_{\pi} \Delta \pi_{t}+\gamma_{y}\left(\Delta y_{t}-\Delta \widetilde{y}_{t}\right)-E_{t} \Delta \pi_{t+1}= \\
\frac{\sigma}{D} E_{t}\left(\Delta y_{t+1}-\Delta y_{t}\right)-\frac{(v-1)}{D} E_{t}\left(\Delta \varepsilon_{t+1}-\Delta \varepsilon_{t}\right)
\end{gathered}
$$

where $\Delta a_{t}=a_{t}-a_{t}^{*}, \Delta \varepsilon_{t}=\varepsilon_{t}-\varepsilon_{t}^{*}$, and $\Delta \widetilde{y}_{t}=\widetilde{y}_{t}-\widetilde{y}_{t}^{*}$.

For illustration purposes, assume that both preference shocks and technology shocks follow an $\operatorname{AR}(1)$ process with persistence $\mu$. Then there is a simple analytical solution to the system (3.19)-(3.20). With this, we may then use (3.17) and (3.18) to obtain the solution for relative consumption and the terms of trade as

$$
\begin{aligned}
c_{t}-c_{t}^{*}= & \frac{\left[(\sigma+\phi D)\left((1-\beta \mu)(1-\mu)+k\left(\gamma_{\pi}-\mu\right)(1+\phi v(2-v))\right)+\gamma_{y} D(1-\beta \mu)(1+\phi v(2-v))\right]}{(\sigma+\phi D) \Delta_{1}} \Delta \varepsilon_{t} \\
& +(v-1)(1+\phi) \frac{\left[k\left(\gamma_{\pi}-\mu\right)(\sigma+\phi D)+\gamma_{y}(1-\beta \mu)(1-\mu)\right]}{(\sigma+\phi D) \Delta_{1}} \Delta a_{t}
\end{aligned}
$$

and

$$
\begin{aligned}
\tau_{t}= & -(v-1) \phi \frac{k\left(\gamma_{\pi}-\mu\right)(\sigma+\phi D)+\gamma_{y}(1-\beta \mu) D}{(\sigma+\phi D) \Delta_{1}} \Delta \varepsilon_{t} \\
& +\sigma(1+\phi) \frac{k\left(\gamma_{\pi}-\mu\right)(\sigma+\phi D)+\gamma_{y}(1-\beta \mu)(1-\mu)}{(\sigma+\phi D) \Delta_{1}} \Delta a_{t}
\end{aligned}
$$

where $\Delta_{1}=\sigma(1-\beta \mu)(1-\mu)+k(\gamma-\mu)(\sigma+\phi D)+\gamma_{y} D(1-\beta \mu)$.

Shocks to preferences of the home country increase home relative consumption, but cause a terms of trade appreciation. Shocks to relative home technology also increase home relative consumption, but cause a terms of trade depreciation. As a result, the correlation between relative consumption and the real exchange rate (which is $v-1$ times the terms of trade) may be negative or positive, depending upon the dominance of preference shocks relative to technology shocks. From (3.21) and (3.22) however, it is clear that the correlation will be affected by the degree of price stickiness. As the Calvo price rigidity parameter $\kappa$ rises, $k$ falls, and both relative consumption and the terms of trade are less and less affected by shocks to technology, particularly if the monetary policy rule places a low weight on the output gap. As a result, the consumption-real exchange rate correlation is more likely to be negative, the greater is the degree of price stickiness. Thus, the observations of deviations from the condition for risk sharing are likely to be affected by the degree of price stickiness, and as a consequence, the stance of monetary policy. 
How does a fixed exchange rate affect the correlation between relative consumption and the real exchange rate? As $\delta \rightarrow \infty$, relative prices can adjust only through domestic and foreign inflation rates. The log change in the exchange rate, defined as $\pi_{s t}$, must be zero. This implies that

$$
\pi_{s t}=\tau_{t}-\tau_{t-1}+\pi_{H t}-\pi_{H t}^{*}=0
$$

Thus, the lagged terms of trade acts as a state variable in the model. Substituting (3.23) and (3.17) into (3.15), we obtain a single equation determining the terms of trade under a fixed exchange rate:

$$
\tau_{t}-\tau_{t-1}=\lambda\left(\tau_{t}-\widetilde{\tau}_{t}\right)+\beta E_{t}\left(\tau_{t+1}-\tau_{t}\right)
$$

where $\lambda=k \frac{(\phi D+\sigma)}{\sigma}$, and $\widetilde{\tau}_{t}=(\phi D+\sigma)^{-1}\left[\sigma(1+\phi) \Delta a_{t}-(v-1) \phi \Delta \varepsilon_{t}\right]$, is the natural terms of trade, or the terms of trade that would obtain under a fully flexible price economy. From (3.24), the terms of trade will adjust gradually to preference or technology shocks, since adjustment must take place through domestic inflation differentials rather than movements in exchange rates. Then, relative consumption can be solved using (3.18). Intuitively, a fixed exchange rate slows down the response of the terms of trade and relative consumption to both shocks.

What does this simple model imply regarding the consumption-real exchange rate correlation? We may first illustrate the impact of preference and technology shocks on relative consumption and the terms of trade under the two alternative exchange rate regimes in Figure 1 . For this figure we use the parameter values in Table 12, which represent a very standard calibration. The discount factor is set at 0.99 . The labor supply elasticity $\phi$ is set at unity. The value for $\kappa$ is set to .75 , giving an average degree of price stickiness of four quarters. The elasticity of intertemporal substitution is set at 0.5 so that $\sigma=2$. The degree of home bias in preferences is set at $v=1.5$, so that imports are 25 percent of GDP in steady state. The persistence of both shocks is set at 0.9. Under a fixed exchange rate, $\delta$ is set at a high value so that the nominal exchange rate is constant (the actual value for $\delta$ is irrelevant once is it set high enough). As regards the monetary policy parameters, we set $\gamma_{\pi}=1.5$, and $\gamma_{y}=0.5$, the standard parameterization under a Taylor rule.

Table 12: Baseline model calibration

\begin{tabular}{|cc|cc|cc|cc|}
\hline \hline$\beta$ & 0.99 & $\sigma$ & 2 & $\rho$ & .01 & $\gamma_{\pi}$ & 1.5 \\
\hline$\phi$ & 1 & $v$ & 1.5 & $\delta$ & 0, or $\lim \delta \rightarrow \infty$ & $\gamma_{y}$ & 0.5 \\
\hline$\kappa$ & 0.75 & $\mu$ & 0.9 & & & & \\
\hline \hline
\end{tabular}

Figures 1(a) and 1(b) show respectively the impact of a negative preference shock at home country on relative consumption and the real exchange rate under inflation targeting and a fixed exchange rate, while figures $1(\mathrm{c})$ and $1(\mathrm{~d})$ show the equivalent responses following a negative technology shock. Figures 1(a) and 1(c) show, as indicated by equations (3.21) and (3.22), that preference shocks and technology shocks have opposite effects on the real exchange rate, but affect consumption in the same direction. A negative correlation between relative consumption and the 
real exchange rate obtains when preference shocks tend to dominate. Figures $1(\mathrm{~b})$ and $1(\mathrm{~d})$ show that, under a fixed exchange rate, the impact on the real exchange rate is substantially dampened. Following a preference shock the real exchange rate depreciates initially, followed by a further depreciation. A technology shock causes an initial appreciation followed by further appreciation. The impact on relative consumption is magnified in response to a preference shock, since the real exchange rate cannot adjust to cushion the impact of the shock. On the other hand, the impact of the technology shock on relative consumption is dampened in a fixed exchange rate regime, because the reduction in the response of the real exchange rate means that there is a smaller response in relative output levels through expenditure switching from home towards foreign goods.

How does the exchange rate peg affect the implied consumption real exchange rate correlation? The sign of the correlation is determined predominantly by the relative volatility of preference shocks to technology shocks. We choose these relative volatilities so that, given other parameters in Table 12, the baseline consumption real exchange rate correlation is equal to -0.1 under an inflation targeting rule, and the volatility of relative consumption is set at 0.02 . Table 13 gives the model's implications for the volatility of consumption, the real exchange rate, and the consumptionreal exchange rate correlation, under an inflation targeting rule and under a fixed exchange rate policy.

Table 13: Policies in the bare-bones model with baseline calibration

\begin{tabular}{|c|c|c|c|c|}
\hline \hline Policy & $\operatorname{stdev}\left(c-c^{*}\right)$ & $\operatorname{stdev}(R E R)$ & $\operatorname{corr}\left(c-c^{*}, R E R\right)$ & $\operatorname{corr}\left(\varepsilon-\varepsilon^{*}, R E R\right)$ \\
\hline$\delta=0$ & .020 & .010 & -0.09 & -0.30 \\
\hline $\lim \delta \rightarrow \infty$ & .022 & .020 & -0.08 & -0.22 \\
\hline \hline
\end{tabular}

Under the inflation targeting rules, the volatility of the real exchange rate is approximately 1 percent. A fixed exchange rate reduces the volatility of the real exchange rate, but also increases the volatility of relative consumption. But despite a lower volatility of the real exchange rate, the consumption-real exchange rate correlation is almost unchanged. Therefore this model, even with sticky prices, does not capture the empirical property documented in the previous section - fixing the nominal exchange rate has essentially no impact on the C-RER correlation here. Hence, the negative C-RER correlation is not driven by the nominal exchange rate in this model, even though prices are sticky, and the exchange rate regime itself does have real effects.

To see why this model cannot reproduce the empirical importance of the nominal exchange rate regime we found in the data, take the following decomposition of the consumption - real exchange rate correlation, obtained using equation (3.18):

$$
\operatorname{corr}\left(c_{t}-c_{t}^{*}, R E R_{t}\right)=\frac{\sqrt{\operatorname{var}\left(R E R_{t}\right)}+\sqrt{\operatorname{var}\left(\varepsilon_{t}-\varepsilon_{t}^{*}\right)} \operatorname{corr}\left(\varepsilon_{t}-\varepsilon_{t}^{*}, R E R_{t}\right)}{\sigma \sqrt{\operatorname{var}\left(c_{t}-c_{t}^{*}\right)}}
$$

Recall that the real exchange rate in this simple model is just $(v-1) \tau_{t}$. The correlation is a function of the standard deviation of the real exchange rate, the standard deviation of relative consumption and relative preference shocks, and the correlation of the real exchange rate and 
relative preference shocks. For this correlation to be negative in the first place, it must obviously be that $\operatorname{corr}\left(\varepsilon_{t}-\varepsilon_{t}^{*}, R E R_{t}\right)<0$, so that demand shocks lead to a real appreciation. The value for $\operatorname{corr}\left(\varepsilon_{t}-\varepsilon_{t}^{*}, R E R_{t}\right)$ in this example is given in the rightmost column of Table 13. Fixing the exchange rate reduces the absolute value of $\operatorname{corr}\left(\varepsilon_{t}-\varepsilon_{t}^{*}, R E R_{t}\right)$, and in principle does the same for $\operatorname{corr}\left(c_{t}-c_{t}^{*}, R E R_{t}\right)$. But the fixed exchange rate also reduces $\sqrt{\operatorname{var}\left(R E R_{t}\right)}$, as shown in column 3 in Table 13. This tends to make $\operatorname{corr}\left(c_{t}-c_{t}^{*}, R E R_{t}\right)$ more negative. In this example, the first factor dominates, so that the value of $\operatorname{corr}\left(c_{t}-c_{t}^{*}, R E R_{t}\right)$ does rise when we move to a fixed exchange rate. But the impact is extremely slight. Hence, the bare-bones sticky price model cannot account for the empirical properties of the C-RER correlation.

How can we amend the model to make it consistent with the empirical findings? From the decomposition above, the critical requirement is that $\operatorname{corr}\left(\varepsilon_{t}-\varepsilon_{t}^{*}, R E R_{t}\right)$ fall by substantially more relative to the fall in $\sqrt{\operatorname{var}\left(R E R_{t}\right)}$ when we move from inflation targeting to fixed exchange rates. One way to facilitate this is by changing the nature of the price adjustment mechanism. Now, instead of the basic Calvo price adjustment model, we follow Woodford (2003) in assuming that newly price setting firms at time $t$ must set prices before they observe time $t$ shocks to preferences or productivity. In the approximated model, this leads to a change in equation (3.19) to:

$$
\Delta \pi_{t}=E_{t-1}\left[k\left(\phi+\frac{\sigma}{D}\right) \Delta y_{t}-\frac{(v-1)}{D} \Delta \varepsilon_{t}-(1+\phi) \Delta a_{t}+\beta E_{t} \Delta \pi_{t+1}\right]
$$

This alters the dynamics of the model, because nominal prices cannot immediately adjust to shocks, even for firms that are re-setting their price. Figure 2 shows how the impulse response to preference and technology shocks are affected, both under inflation targeting and under fixed exchange rates. The responses under inflation targeting differ only slightly from those in the baseline model - there is one period of adjustment after which new prices are updated. Under a fixed exchange rate, however, the real exchange rate cannot adjust at all in response to a shock. This significantly reduces the impact of a preference shock on the real exchange rate (panel (b) of Figure 2), thus reducing the (absolute) value of $\operatorname{corr}\left(\varepsilon_{t}-\varepsilon_{t}^{*}, R E R_{t}\right)$.

Table 14 illustrates the effect of this alternative price setting assumption (all other parameter and shock settings are as in Table 12).

Table 14: Policies in the bare-bones model with ex-ante pricing

\begin{tabular}{|c|c|c|c|c|}
\hline \hline Policy & $\operatorname{stdev}\left(c-c^{*}\right)$ & $\operatorname{stdev}(R E R)$ & $\operatorname{corr}\left(c-c^{*}, R E R\right)$ & $\operatorname{corr}\left(\varepsilon-\varepsilon^{*}, R E R\right)$ \\
\hline$\delta=0$ & .020 & .008 & -0.10 & -0.30 \\
\hline $\lim \delta \rightarrow \infty$ & .021 & .006 & 0.02 & -0.10 \\
\hline \hline
\end{tabular}

As before, moving from inflation targeting to a fixed exchange rate increases the volatility of relative consumption and reduces the volatility of the real exchange rate. But the key difference from Table 13 is that the fixed exchange rate policy leads to a large increase in $\operatorname{corr}\left(\varepsilon-\varepsilon^{*}, R E R\right)$. Using the decomposition from (3.25), this leads to a reversal in the sign of $\operatorname{corr}\left(c-c^{*}, R E R\right)$. Hence, $\operatorname{corr}\left(c-c^{*}, R E R\right)$ becomes positive, and in principle, the bare-bones model amended to 
allow for ex-ante price setting can be made consistent with evidence on the importance of the nominal exchange rate for the consumption-real exchange rate correlation.

\subsection{A more general model with incomplete markets and non-traded goods}

While the previous model set out the ingredients necessary to account for the importance of the nominal exchange rate for the consumption-real exchange rate correlation, it did not allow for a substantial quantitative evaluation of the impact of the exchange rate regime under sticky prices. For instance, the real exchange rate in that model is driven only by differences in the composition of the consumption basket across countries, and in addition, we assumed that international financial markets were complete, so that only shocks to preferences could break the direct link between real exchange rates and relative consumption. In this section, we develop a more elaborate model which is closer in structure to the current literature. We amend the model to allow for incomplete financial markets. In addition, the model is driven by different types of technology shocks, which facilitates a negative consumption-real exchange rate correlation even in the absence of preference shocks. The structure of the model is similar to that of Benigno and Thoenissen (2008).

We briefly sketch out the details of the extended model. Again, there are two countries, home and foreign, with the population of each country is normalized at unity. Home country preferences

are defined as in (3.7), except, for a) we now abstract from preference shocks, and b) we now assume that the composite consumption good is defined as:

$$
C_{t}=\left(\varrho^{\frac{1}{\varphi}} C_{T t}^{1-\frac{1}{\varphi}}+(1-\varrho)^{\frac{1}{\varphi}} C_{N t}^{1-\frac{1}{\varphi}}\right)^{\frac{\varphi}{1-\varphi}}
$$

where $C_{T t}$ and $C_{N t}$ represent respectively, the composite consumption of traded and non-traded goods. The elasticity of substitution between traded and non-traded goods is $\varphi$. Traded consumption in turn is decomposed into consumption of home goods, and foreign goods, as follows:

$$
C_{T t}=\left(\left(\frac{v}{2}\right)^{\frac{1}{\lambda}} C_{H t}^{1-\frac{1}{\lambda}}+\left(1-\frac{v}{2}\right)^{\frac{1}{\lambda}} C_{F t}^{1-\frac{1}{\lambda}}\right)^{\frac{\lambda}{1-\lambda}},
$$

where $\lambda$ is the elasticity of substitution between home and foreign traded good. Again, in each case, we assume that consumption sub-aggregates are differentiated across the consumption of individual goods, with elasticity of substitution $\theta>1$ across goods.

These consumption aggregates imply the following price index definitions:

$$
\begin{aligned}
P_{t} & =\left(\varrho P_{T t}^{1-\varphi}+(1-\varrho) P_{N t}^{1-\varphi}\right)^{\frac{1}{1-\varphi}} \\
P_{T t} & =\left(\frac{v}{2} P_{H t}^{1-\lambda}+\left(1-\frac{v}{2}\right) P_{F t}^{1-\lambda}\right)^{\frac{1}{1-\lambda}}
\end{aligned}
$$

where $P_{T t}$ and $P_{N t}$ represent traded and non-traded price levels, and $P_{H t}$ and $P_{F t}$ are retail prices 
of home exportables and foreign importables. We define the real exchange rate as before:

$$
R E R_{t}=\frac{S_{t} P_{t}^{*}}{P_{t}}
$$

We assume that international financial markets are incomplete in the sense that financial trade takes place via non-contingent one period nominal bonds. The home budget constraint is given by:

$$
P_{t} C_{t}+B_{t+1}+\frac{S_{t} B_{t+1}^{*}}{\Theta\left(\frac{S_{t} B_{t+1}^{*}}{P_{t}^{*}}\right)}=W_{t} N_{t}+\Pi_{t}+R_{t} B_{t}+R_{t}^{*} S_{t} B_{t}^{*} .
$$

where $B_{t+1}\left(B_{t+1}^{*}\right)$ indicates home (foreign) currency bond holdings of the home household, $W_{t}$ represents the nominal wage, assumed to be equalized across sectors, and $\Pi_{t}$ represents profits from the home firm plus net transfers from the government. The function $\Theta\left(\frac{S_{t} B_{t+1}^{*}}{P_{t}}\right)$ satisfies $\Theta(\bar{b})=1, \quad \Theta^{\prime}>0, \Theta^{\prime \prime}>0$, and represents a transactions cost of foreign bond holdings, which is a standard approach to induce stationarity in open economy models with incomplete markets (see Schmitt-Grohe and Uribe (2003)).

Households choose consumption of individual goods, labor supply in each sector, and bond holdings in the usual way. Preferences, budget constraints, and choices of foreign households are determined in an analogous fashion. The critical difference from the previous section is that we no longer employ the full risk sharing condition given by (3.8). Instead, given an integrated world bond market the state by state risk sharing condition (3.8) is replaced with the conditional risk sharing condition given by:

$$
E_{t} \frac{C_{t+1}^{-\sigma}}{C_{t}^{-\sigma}} \frac{S_{t+1}}{P_{t+1}} \frac{P_{t}}{S_{t}} \Theta(.)=E_{t} \frac{C_{t+1}^{*-\sigma}}{C *_{t}^{-\sigma}} \frac{P_{t}^{*}}{P_{t+1}^{*}}
$$

As in the recent literature (see e.g. Corsetti, Dedola, and Leduc (2008), Kollmann (2009b), Benigno and Thoenissen (2008)), this condition implies that up to a first-order approximation, expected consumption growth differentials across countries are positively related to expected changes in the real exchange rate (conditional on the small portfolio adjustment costs).

Firms in each sector produce using capital and labor. A typical firm in the non-traded (traded) sector has production function $Y_{N t}(i)=A_{N t} N_{N t}(i)^{(1-\alpha)} K_{N t}(i)^{\alpha},\left(Y_{H t}(i)=A_{H t} N_{H t}(i)^{(1-\alpha)} K_{H t}(i)^{\alpha}\right)$. Thus, there are two technology shocks - shocks to the non-traded sector $A_{N t}$, and to the traded sector $A_{H t}$. These shocks play substantially different roles in determining the consumption-real exchange rate correlation. Firms choose their path of investment so as to attain an optimal capital stock, where the relationship between investment and capital for a non-traded (traded) firm is $K_{N t+1}(i)=\left(1-\delta_{K}\right) K_{N t}(i)+\phi\left(\frac{I_{N t}}{K_{N t}}\right) K_{N t}\left(K_{H t+1}(i)=\left(1-\delta_{K}\right) K_{H t}(i)+\phi\left(\frac{I_{H t}}{K_{H t}}\right) K_{H t}\right)$, where $\phi^{\prime}()>0,. \phi^{\prime \prime}()<$.0 , represents adjustment cost technology for investment, where the cost is directly incurred by the firm. $\delta_{K}$ is the depreciation rate for capital.

Firms in each sector set prices following a Calvo price adjustment specification, using domestic households nominal marginal rates of substitution as stochastic discount factors. We allow for 
differences in the Calvo probabilities of price adjustment across traded and non-traded goods sector firms. The optimal pricing, employment, and investment policy for firms are standard. As before, we initially illustrate the workings of the model for a standard Calvo pricing framework, and then show how the assumption of ex-ante pricing affects the results.

Monetary policy is set in the same way as before. The home country monetary authority follows an Taylor rule adjusted for nominal exchange rate changes, except that it targets the consumer price inflation so that the nominal interest rate in the home economy is $r_{t}=\rho+\gamma_{\pi} \pi_{t}+\delta\left(S_{t}-S_{t-1}\right)$, where $\pi_{t}=p_{t}-p_{t-1}$. The foreign monetary rule is given by $r_{t}^{*}=\rho+\gamma_{\pi} \pi_{t}^{*} \cdot{ }^{26}$

Finally, goods market clearing conditions are given as:

$$
\begin{aligned}
Y_{H t} & =C_{H t}+C_{H t}^{*}+I_{H t}+I_{N t} \\
Y_{F t}^{*} & =C_{F t}+C_{F t}^{*}+I_{F t}^{*}+I_{N t}^{*}, \\
Y_{N t} & =C_{N t}, \\
Y_{N t}^{*} & =C_{N t}^{*} .
\end{aligned}
$$

\subsection{The consumption - real exchange rate correlation in the extended model}

The full linear approximation of the model is more involved than the simple framework of the last subsection. There are two forward looking inflation equations in each country - for the traded goods and non-traded goods sector separately. In addition, the real exchange rate is now determined jointly by movements in the terms of trade and the internal relative price ratio of traded to nontraded goods. The linear approximation to (3.28) is given by:

$$
E_{t}\left(\Delta c_{t+1}-\Delta c_{t+1}^{*}\right)=\frac{1}{\sigma} E_{t} \Delta R E R_{t+1}+\frac{1}{\sigma} \overline{\Theta C}^{\prime \prime} \widehat{b}_{t+1}
$$

where $\Delta c_{t+1}=c_{t+1}-c_{t}$, etc. The last term on the right hand side represents the wedge in consumption growth, for given real exchange rates, associated with differential home country costs of foreign bond holdings. Again, this represents a very small term, and has no first-order implication for the relationship between relative consumption and real exchange rates.

The real exchange rate itself is defined by:

$$
R E R_{t}=\rho\left(\tau_{N t}^{*}-\tau_{N t}\right)+(1-\rho)(v-1) \tau_{t}+\rho \tau_{t}
$$

Here $\tau_{N t}=p_{N t}-p_{H t}, \tau_{N t}^{*}=p_{N t}^{*}-p_{F t}^{*}$, and $\tau_{t}$ is the terms of trade as defined before. The real exchange rate then moves for two reasons. First, cross country differences in internal relative prices will affect $R E R$, so that for instance, if the foreign country relative price of non-traded goods rises relative to the home country relative price, there will be a home real depreciation. Secondly, as before, the real exchange rate is affected by the external terms of trade $\tau_{t}$.

Unlike the previous model, this extended model allows for a negative correlation between rela-

\footnotetext{
${ }^{26}$ The dynamics of the model are changed only slightly if we allow for an output term in the monetary policy rule.
} 
tive consumption and the real exchange rate, even in the absence of preference shocks. As shown by Benigno and Thoenissen (2008) and Corsetti, Dedola, and Leduc (2008), even if relative consumption and real exchange rates are positively correlated in conditional expectations, they may be ex-post negatively correlated due to the presence of unanticipated shocks which move relative consumption and the real exchange rate in different directions. A clear example in the present model is a shock to the productivity of the traded good sector. In an incomplete markets setting, this shock would be expected to raise home consumption relative to foreign consumption, but due to an increased relative demand for non-traded goods, it can also lead to a real exchange rate appreciation.

There are two types of shocks in the extended model - shocks to productivity in each of the sectors. We let each shock be $\operatorname{AR}(1)$ with persistence $\mu_{N}$, and $\mu_{T}$ with standard deviations of the innovations given by $\sigma_{N}$ and $\sigma_{T}$, respectively.

We must extend the calibration of Table 12 for this extended model. Table 15 describes the extended calibration.

Table 15: Extended model calibration

\begin{tabular}{|cc|cc|cc|cc|cc|cc|cc|}
\hline \hline$\beta$ & 0.99 & $\sigma$ & 2 & $\rho$ & 0.6 & $\alpha$ & 0.33 & $\frac{\bar{\phi}^{\prime \prime} \overline{\overline{i k}}}{\bar{\phi}^{\prime}}$ & -0.75 & $\sigma_{N}$ & 0.7 & $\delta$ & 0, or $\lim \delta \rightarrow \infty$ \\
\hline$\phi$ & 1 & $\varphi$ & .5 & $v$ & 1.25 & $\kappa_{N}$ & 0.8 & $\mu_{N}$ & 0.3 & $\sigma_{T}$ & 1.9 & & \\
\hline $\bar{\Theta}^{\prime}(.) \bar{C}$ & 0.0025 & $\lambda$ & 2 & $\delta_{K}$ & 0.025 & $\kappa_{T}$ & 0.67 & $\mu_{T}$ & 0.85 & $\gamma_{\pi}$ & 1.5 & & \\
\hline
\end{tabular}

Again, we set the elasticity of intertemporal substitution in consumption equal to 0.5 , and the labor supply elasticity $\phi=1$. The elasticity of substitution between non-traded and traded goods is usually estimated to be substantially below unity, so we set $\varphi=0.5$, midway between the estimates of Stockman and Tesar (1995) and Mendoza (1995). The elasticity of substitution between home and foreign goods is set at $\lambda=2$, a benchmark estimate. But the focus of the discussion below will be on the allowing for variations in $\lambda$ that impact on the C-RER correlation, and in particular the implications of exchange rate policy for this correlation. We assume that the non-traded goods sector is 60 percent of GDP, somewhat smaller than that of the US economy, but larger than that for smaller economies. The degree of home bias in the traded goods sector is set at $v=1.25$, half of the estimate of the previous simple model, since the traded goods sector is much smaller in this model. We follow Ghironi and Melitz (2005) in setting the elasticity of the bond adjustment cost equal to 0.0025 . The elasticity of the marginal investment adjustment cost function at the steady state is set to reproduce a ratio of investment to output volatility approximately equal to 3 . In the baseline setting, this implies that $\frac{\bar{\phi}^{\prime \prime} \overline{i / k}}{\bar{\phi}^{\prime}}=-0.75$. The depreciation rate on capital is set to equal 0.025 at quarterly frequency. Capital share in the production function is set to 0.33.

The degree of price rigidity is likely to be substantially higher in the non-traded goods sector than in the traded goods sector. Nakamura and Steinsson (2008) measure the median duration of fixed prices in the US service sector to be 5 quarters, and 3 quarters for the non-service sector. We use these measures to set $\kappa_{N}=0.8$ and $\kappa_{T}=0.67$. In measuring the persistence and volatility of 
productivity shocks to the traded and non-traded sector, we follow Benigno and Thoenissen (2008). They measure traded sector productivity shocks to have persistence 0.85 and standard deviation of 1.9 percent, while non-traded shocks are much less persistent and less volatile, with $\mu_{N}=0.3$ and $\sigma_{N}=0.7$. In addition, we impose the covariance structure of shocks as estimated by Benigno and Thoenissen (2008). ${ }^{27}$

\subsection{Results with the extended model}

Figure 3 presents the impulse responses of consumption and RER to a negative shock to traded sector productivity in home country in the extended model. Figure 4 reports the corresponding impulse responses following a negative shock to non-traded sector productivity in the extended model. Both Figures contrast the dynamics of consumption and RER under flexible and under fixed exchange rate regimes (the latter is indicated by letter $\mathrm{F}$ ).

As panel (a) of Figure 3 illustrates, a negative shock to the traded goods productivity causes a fall in home relative consumption, and a real exchange rate depreciation. Given the persistence of shocks, and open international bond markets, these shocks have very persistent effects in the model. Panel (b) of the Figure describes the composition of real exchange rate adjustment. Following a negative productivity shock in traded sector, there is a fall in $\tau_{t}$, i.e. a terms of trade appreciation, as the global supply of the home export good is reduced. But at the same time, the income effect of the home productivity fall leads to a decline in demand for non-traded goods, which leads to a fall in $\tau_{N t}$, or a rise in $\tau_{N t}^{*}-\tau_{N t}$. The first effect tends towards a real exchange rate appreciation, while the second causes a real depreciation. In the baseline model, the second effect dominates, so we get a simultaneous depreciation and a fall in relative consumption.

How does fixing the exchange rate affect the response of relative consumption and the real exchange rate? From the Figure, we see that the impact is very slight. Fixing the exchange rate leads to a slightly smaller real exchange rate depreciation, and a slightly larger fall in relative consumption. Panel (b) shows that this is achieved by a slightly greater terms of trade appreciation, and a slightly smaller relative non-traded goods price increase.

The bottom two panels of Figure 3 make clear why the difference between the two cases is so small. In panel (c) we see that the real exchange rate depreciation is achieved by a nominal depreciation, a disinflation in the non-traded goods sector, which is partially being offset by a positive inflation in the home goods sector. When the exchange rate is fixed, as in panel $(\mathrm{d})$, the disinflation in the non-traded goods sector is substantially magnified, and the inflation in the home goods sector is weakened. Hence, we achieve an almost identical outcome for the real exchange rate due to different responses of sectoral inflation rates under fixed exchange rates.

\footnotetext{
${ }^{27}$ In particular, taking the shock innovations at $\varepsilon=\left[\varepsilon_{H}, \varepsilon_{F}^{*}, \varepsilon_{N}, \varepsilon_{N}^{*}\right]^{\prime}$, they estimate the covariance matrix for shocks to traded and non-traded goods productivity innovations as $\operatorname{Var}(\varepsilon)=$

$\left[\begin{array}{cccc}3.76 & 1.59 & 0.72 & 0.44 \\ 1.59 & 3.76 & .44 & .72 \\ .72 & .55 & .51 & .21 \\ .44 & .72 & .21 & .51\end{array}\right]$
}


Figure 4 gives the same breakdown for the case of negative shock to non-traded sector productivity. ${ }^{28}$ Such negative shock reduces home relative consumption and causes a real exchange rate appreciation. Again, the real exchange rate and relative consumption response is similar for a fixed and flexible nominal exchange rate. Under flexible exchange rates, this is achieved primarily by nominal appreciation. Under fixed exchange rate, it is achieved by average inflation rates in excess of those in the foreign country. ${ }^{29}$

A number of studies (see, for instance, Heathcote and Perri (2002)) have shown that the the elasticity of substitution between the traded goods is a key parameter in the class of models considered above. Therefore, we next investigate how our results are affected by the trade elasticity. Figure 5 illustrates the impact of a traded sector productivity shock for a value of $\lambda=5$, a higher elasticity than in the benchmark case. Now there is a smaller terms of trade appreciation, due to the a higher elasticity of substitution between traded goods. This leads to a substantially greater real exchange rate depreciation under flexible exchange rates, with the nominal exchange rate playing a greater role. Then fixing the exchange rate has a greater impact on the real exchange rate, because it is harder to achieve the greater depreciation with domestic disinflation.

Figure 6 illustrates the results for the C-RER correlation, when we simulate the model including both shocks, under the persistence and covariance structure of Table 15. The Figure illustrates the difference between the correlation $\operatorname{corr}\left(\Delta\left(c-c^{*}\right), \Delta R E R\right)$, under a fixed and flexible exchange rate regimes, as a function of the size of the trade elasticity $\lambda$. With $\lambda$ close to unity, the correlation is equal to unity, since we have effectively complete markets in that case. As $\lambda$ increase, we find that the correlation is systematically lower for a flexible exchange rate policy than under fixed exchange rates. However, for values of $\lambda$ in the range of 2 , the difference is very slight. As $\lambda$ rises more and more, the correlation becomes negative under both exchange rate policies.

Table 16 reports the simulation results for the extended model at the benchmark value of $\lambda=2$. As before, the fixed exchange rate leads to a rise in the volatility of consumption and a fall in the volatility of the real exchange rate. The value of $\operatorname{corr}\left(c-c^{*}, R E R\right)$ is slightly positive under fixed exchange rates, and slightly negative under flexible exchange rates.

Table 16: Policies in the extended model

\begin{tabular}{|c|c|c|c|c|c|}
\hline Policy & $\operatorname{stdev}\left(c-c^{*}\right)$ & $\operatorname{stdev}(R E R)$ & $\operatorname{corr}\left(c-c^{*}, R E R\right)$ & $\operatorname{stdev}(y)$ & $\operatorname{stdev}(I)$ \\
\hline$\delta=0$ & .85 & .64 & -0.05 & 1.65 & 4.3 \\
\hline $\lim \delta \rightarrow \infty$ & .92 & .42 & 0.04 & 1.63 & 4.2 \\
\hline \hline
\end{tabular}

\footnotetext{
${ }^{28}$ For comparison purposes, in this Figure we use the same shock persistence as in Figure 2. In the simulations below we use the baseline shock persistence for non-traded productivity shocks that is stated in Table 15 .

${ }^{29}$ Note that Figure 4 Panel (d) shows that inflation rates in both sectors are negative. But this is still consistent with real appreciation because foreign inflation rates are negative also, given the fall in aggregate demand following the negative home country productivity shock. On average, CPI inflation in the foreign country is lower than that in the home country, so under a fixed exchange rate, the home real exchange rate appreciates.
} 


\subsubsection{Ex-ante Pricing in the Extended Model}

Figure 6 shows that the extended model can account for a difference in sign between $\operatorname{corr}(\Delta(c-$ $\left.c^{*}\right), \Delta R E R$ ) under fixed and flexible exchange rates, but this gap is both small and tenuous in the sense that it is robust only for a relatively small range of values for the trade elasticity $\lambda$. For $\lambda$ to close to unity, the correlation is positive and close to unity whatever the exchange rate regime, in clear violation of the data. But for $\lambda$ much above 2 , the correlation becomes negative, under both fixed and flexible exchange rates.

In the previous section, we showed that the assumption of ex-ante pricing had a significant effect in accounting for the importance of the exchange rate regime for the consumption-real exchange rate correlation. How does the timing of price setting affect the results here? We now follow the same logic as before and alter the pricing technology so that price-adjusting firms in both sectors have to choose their prices before the current state of the world is known. As before, this means that in response to either type of shocks, the only component of the real exchange rate that can adjust immediately is the nominal exchange rate. Figure 7 shows the impulse response to a negative shock to traded goods technology with the ex-ante price setting assumption. Now, under a fixed exchange rate, the real exchange rate is predetermined within the period. This alteration significantly magnifies the gap between real exchange rate responses under fixed and flexible exchange rate regimes.

Figure 8 illustrates the counterpart of Figure 6 for the extended model, in the case of ex-ante pricing. We now see that there is a significant gap between $\operatorname{corr}\left(\Delta\left(c-c^{*}\right), \Delta R E R\right)$ under fixed and flexible exchange rates. Moreover, this is robust to a large range of values for $\lambda$. In addition, $\operatorname{corr}\left(\Delta\left(c-c^{*}\right), \Delta R E R\right)$ is consistently positive under fixed exchange rates, and negative under flexible exchange rates. Hence we may conclude that in principle, the extended model, based on the elements of incomplete markets, differential sectoral shocks, sticky prices, and ex-ante price setting, can account for both the consumption - real exchange anomaly, and the empirical feature that this anomaly seems to be a property of floating exchange rate regimes.

Table 17 presents the simulation results under ex-ante pricing. Again we see that there is a substantial impact of the exchange rate regime on the consumption real exchange rate correlation.

Table 17: Policies in the extended model with ex-ante pricing

\begin{tabular}{|c|c|c|c|c|c|}
\hline Policy & $\operatorname{stdev}\left(c-c^{*}\right)$ & $\operatorname{stdev}(R E R)$ & $\operatorname{corr}\left(c-c^{*}, R E R\right)$ & $\operatorname{stdev}(y)$ & $\operatorname{stdev}(I)$ \\
\hline$\delta=0$ & .79 & .51 & -0.12 & 1.51 & 3.73 \\
\hline $\lim \delta \rightarrow \infty$ & .90 & .37 & 0.22 & 1.51 & 3.72 \\
\hline \hline
\end{tabular}

\section{Conclusions}

In this paper we have explored the nature of consumption risk sharing within and between countries, and highlighted the key feature that the deviation from the predictions of consumption risk sharing 
seem to be associated with the presence of nominal exchange rate flexibility. Using both regional and international data, we showed that a 'border dummy' led to a significant negative correlation between relative consumption growth and real exchange rate changes. Moreover, this border dummy is substantially accounted for by movements in the nominal exchange rate. We then asked whether this feature of the data was consistent with the results of standard sticky price open economy models, in which real allocations are affected by the exchange rate regime. We argue that the standard model is not consistent with empirical observations, whether we focus on a simple 'bare bones' model, or a more elaborate multi-sector model featuring incomplete markets and endogenous capital accumulation. The key difficulty in explaining the reversal of the sign of the consumption real exchange rate correlation between fixed and flexible exchange rate regimes is that in the standard model, the behavior of the real exchange rate is not fundamentally different between fixed and floating exchange rates, since prices are forward looking, and fixing exchange rates gives rise to greater nominal price adjustment in response to shocks. Adjusting the standard model to incorporate ex-ante price setting however significantly improves the ability of the model to explain the data. In that case, we found that the consumption real exchange rate correlation tends to switch signs between flexible and fixed exchange rate regimes, and that this is a robust property of the model.

While we have outlined one mechanism which can account for the importance of the nominal exchange rate for the observed consumption real exchange rate correlation, we are hesitant to claim that this provides a full account of the importance of the exchange rate in cross country risk sharing. The main reason is that this model entirely fails to explain the observed volatility of real exchange rates. This failure is quite standard in the literature (see Benigno and Thoenissen (2008), for instance). From Table 1, it is clear that relative price variability is much larger when calculated between regions in different countries than when comparing across regions within a country. To the extent that this is an implication of flexible exchange rates, this should imply both that real exchange rate volatility falls by orders of magnitude when comparing fixed and flexible exchange rates, and that real exchange rate volatility is substantially larger than relative consumption volatility. Neither property comes out of the models presented in the paper. Thus, we may conclude from the models developed above that while it is possible to provide an account of the factors under which the consumption - real exchange rate correlation should depend on the nominal exchange rate, absent a full explanation of differential real exchange rate volatility across nominal exchange rate regimes (i.e. the classic Mussa (1986) paradox), the full explanation remains incomplete at present. 


\section{References}

Asdrubali, P., B. Sørensen, and O. Yosha (1996): "Channels of Interstate Risksharing: United States 1963-1990," Quarterly Journal of Economics, 111, 1081-1110.

Athanasoulis, S. G., and E. Van Wincoop (2001): "Risk Sharing Within the United States: What do Financial Markets and Fiscal Federalism Accomplish?," The Review of Economics and Statistics, 83(4), 688-698.

Backus, D. K., And G. W. Smith (1993): "Consumption and Real Exchange Rates in Dynamic Economies with Non-traded Goods," Journal of International Economics, 35(3-4), 297-316.

Bayoumi, T., and M. W. Klein (1997): "A Provincial View of Economic Integration," IMF Staff Papers, 44(4), 534-556.

Benigno, G., P. Benigno, and F. Ghironi (2007): "Interest rate rules for fixed exchange rate regimes," Journal of Economic Dynamics and Control, 31(7), 2196-2211.

Benigno, G., and C. Thoenissen (2008): "Consumption and Real Exchange Rates with Incomplete Markets and Non-traded Goods," Journal of International Money and Finance, 27(6), 926-948.

Chari, V. V., P. J. Kehoe, and E. R. McGrattan (2002): "Can Sticky Price Models Generate Volatile and Persistent Real Exchange Rates?," Review of Economic Studies, 69(3), 533-63.

Clarida, R., J. Gali, and M. Gertler (2002): "A simple framework for international monetary policy analysis," Journal of Monetary Economics, 49(5), 879-904.

Corsetti, G., L. Dedola, and S. Leduc (2008): "International Risk Sharing and the Transmission of Productivity Shocks," Review of Economic Studies, 75(2), 443-473.

Crucini, M. (1999): "On International and National Dimensions of Risksharing," The Review of Economics and Statistics, 81(1), 73-84.

Del Negro, M. (2002): “Asymmetric Shocks Among U.S. States," Journal of International Economics, 56(2), 273-297.

Devereux, M. B., And C. Engel (2003): "Monetary Policy in the Open Economy Revisited: Price Setting and Exchange-Rate Flexibility," Review of Economic Studies, 70(4), 765-783.

Devereux, M. B., G. W. Smith, and J. Yetman (2009): "Consumption and Real Exchange Rates in Professional Forecasts," NBER Working Papers 14795, National Bureau of Economic Research, Inc.

Engel, C. (1999): "Accounting for U.S. Real Exchange Rate Changes," Journal of Political Economy, 107(3), 507-538. 
Engel, C., And J. Rogers (1996): "How wide is the border?," The American Economic Review, 86(5), 1112-1125.

Ghironi, F., and M. J. Melitz (2005): "International Trade and Macroeconomic Dynamics with Heterogeneous Firms," The Quarterly Journal of Economics, 120(3), 865-915.

Gorodnichenko, Y., and L. Tesar (2009): "Border effect or country effect? Seattle may not be so far from Vancouver after all," American Economic Journal: Macroeconomics, 1(1), 219-241.

Hadzi-Vaskov, M. (2008): "Does the Nominal Exchange Rate Explain the Backus-Smith Puzzle? Evidence from the Eurozone," Working Papers 07-32, Utrecht School of Economics.

Heathcote, J., And F. Perri (2002): "Financial autarky and international business cycles," Journal of Monetary Economics, 49(3), 601-627.

Hess, G., And K. Shin (1998): "Intranational Business Cycles in the United States," Journal of International Economics, 44, 289-314.

Hess, G. D., And K. Shin (2000): "Risk Sharing by Households Within and Across Regions and Industries," Journal of Monetary Economics, 45(3), 533-560.

Hess, G. D., And K. Shin (2010): "Understanding the Backus-Smith puzzle: It's the (nominal) exchange rate, stupid," Journal of International Money and Finance, 29(1), 169-180.

Heston, A., R. Summers, and B. Aten (2006): "Penn World Table Version 6.2," Database, Center for International Comparisons of Production, Income and Prices at the University of Pennsylvania.

Kollmann, R. (1995): "Consumption, Real Exchange Rates and the Structure of International Asset Markets," Journal of International Money and Finance, 14(2), 191-211.

Kollmann, R. (2009a): "Household Heterogeneity and the Real Exchange Rate: Still a Puzzle," CEPR Discussion Papers 7301, C.E.P.R. Discussion Papers.

- (2009b): "Limited Asset Market Participation and the Consumption-Real Exchange Rate Anomaly," CEPR Discussion Papers 7452, C.E.P.R. Discussion Papers.

Mendoza, E. G. (1995): "The Terms of Trade, the Real Exchange Rate, and Economic Fluctuations," International Economic Review, 36(1), 101-37.

Mussa, M. (1986): "Nominal exchange rate regimes and the behavior of real exchange rates: Evidence and implications," Carnegie-Rochester Conference Series on Public Policy, 25(1), 117214.

Nakamura, E., and J. Steinsson (2008): "Five Facts about Prices: A Reevaluation of Menu Cost Models," The Quarterly Journal of Economics, 123(4), 1415-1464. 
Obstfeld, M., And K. Rogoff (1996): Foundations of International Macroeconomics. MIT Press Cambridge, MA.

OkaWa, Y., And E. VAn Wincoop (2010): "Gravity in International Finance," Working Papers 072010, Hong Kong Institute for Monetary Research.

Portes, R., And H. Rey (2005): "The determinants of cross-border equity flows," Journal of International Economics, 65(2), 269-296.

Schmitt-Grohe, S., And M. Uribe (2003): "Closing small open economy models," Journal of International Economics, 61(1), 163-185.

Stockman, A. C., And L. L. Tesar (1995): "Tastes and Technology in a Two-Country Model of the Business Cycle: Explaining International Comovements," American Economic Review, $85(1), 168-185$.

Van Wincoop, E. (1995): "Regional Risksharing," European Economic Review, 39, 1545-1567.

Woodford, M. (2003): Interest and Prices: Foundations of a Theory of Monetary Policy. Princeton University Press. 
Figure 1: Impulse responses in the bare-bones model
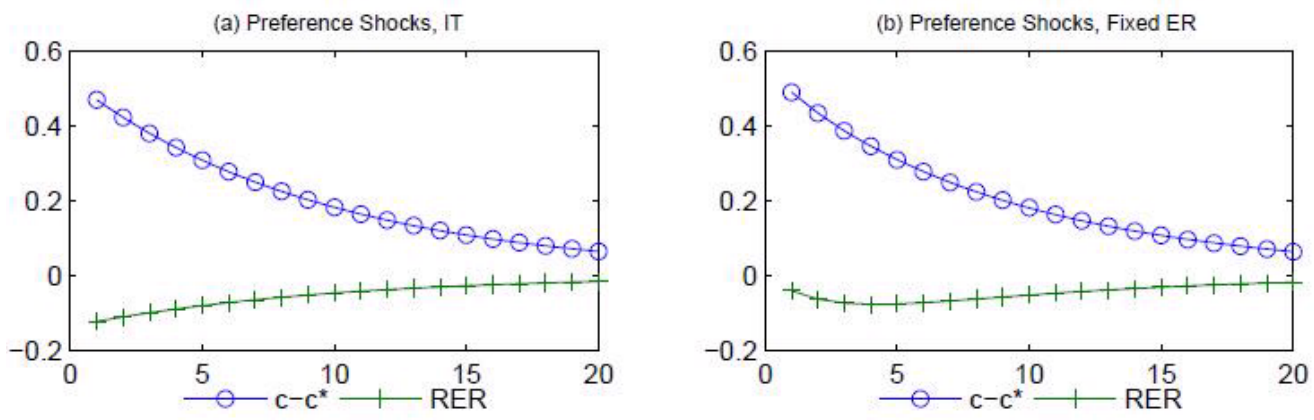

(c) Technology Shocks, IT
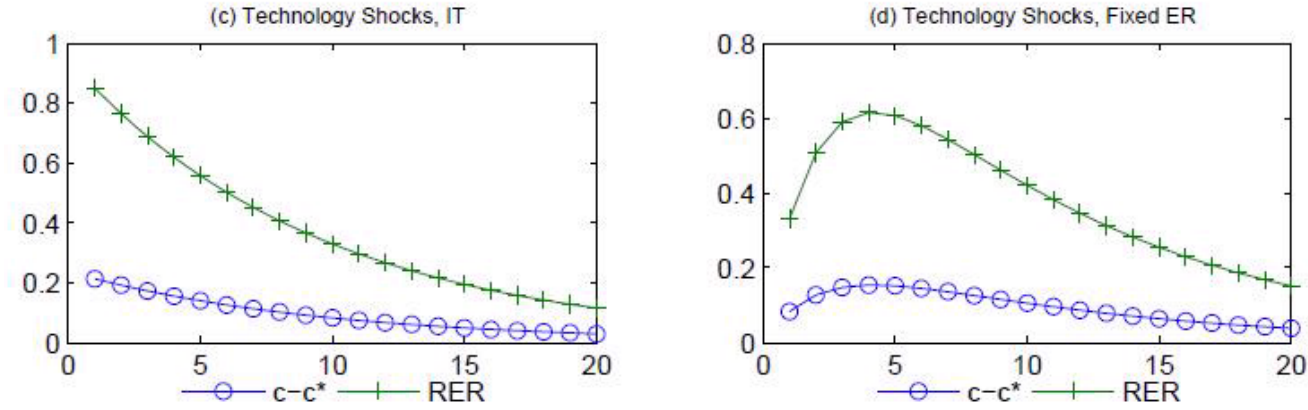

Notes: The figures present the impulse responses of home country's relative consumption and RER to preference and technology shocks in the bare-bones model under benchmark calibration. Panels on the left ((a) and (c)) refer to the inflation targeting regime, while panels one the right ((b) and (d)) are the responses under a fixed exchange rate regime. 
Figure 2: Impulse responses in the bare-bones model with ex-ante pricing
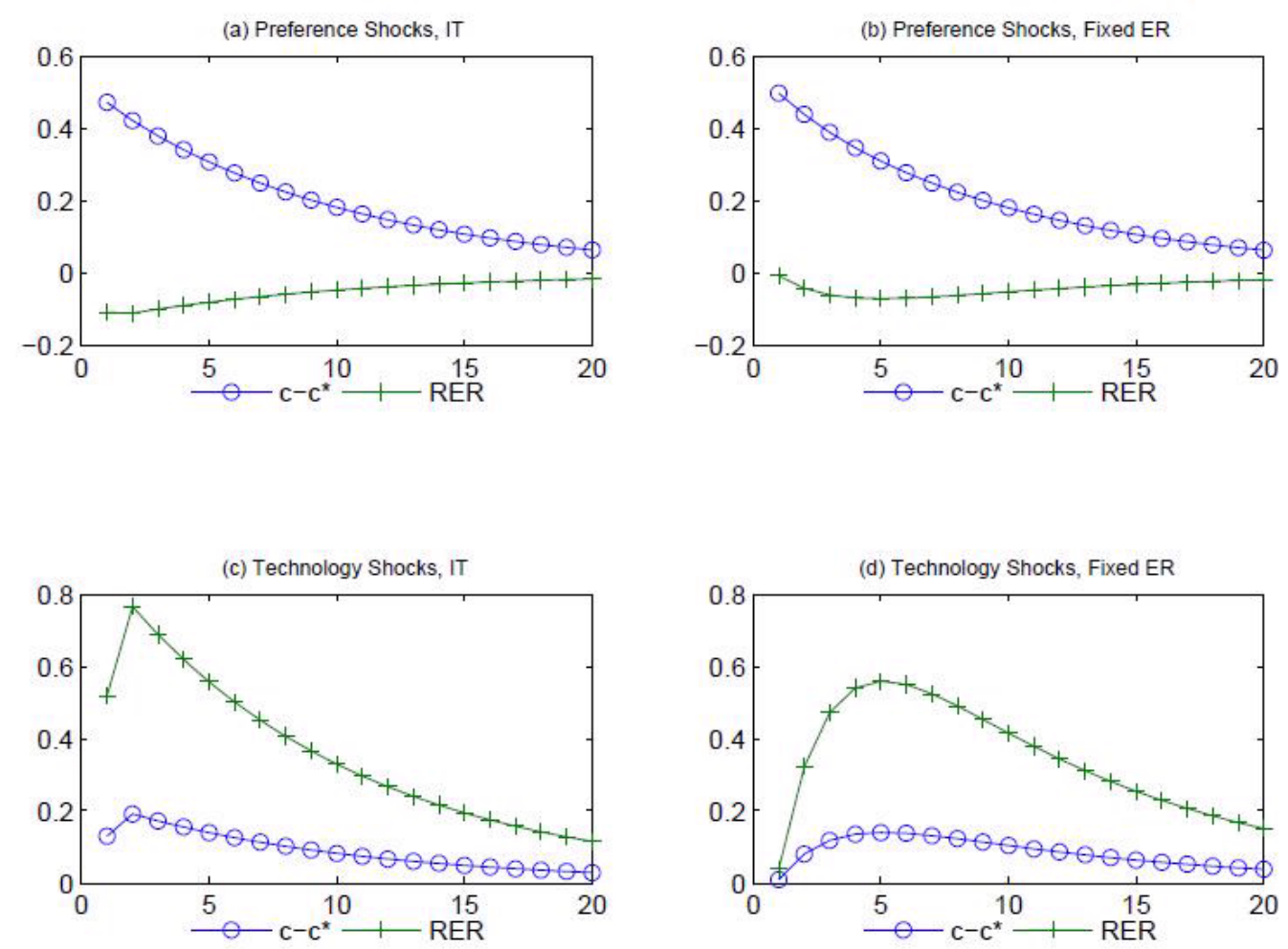

Notes: The figures present the impulse responses of home country's relative consumption and RER to preference and technology shocks in the bare-bones model with ex-ante pricing. Panels on the left ((a) and (c)) refer to the inflation targeting regime, while panels one the right ((b) and (d)) are the responses under a fixed exchange rate regime. 
Figure 3: Impulse responses following a negative shock to $\mathrm{T}$ sector productivity in the extended model
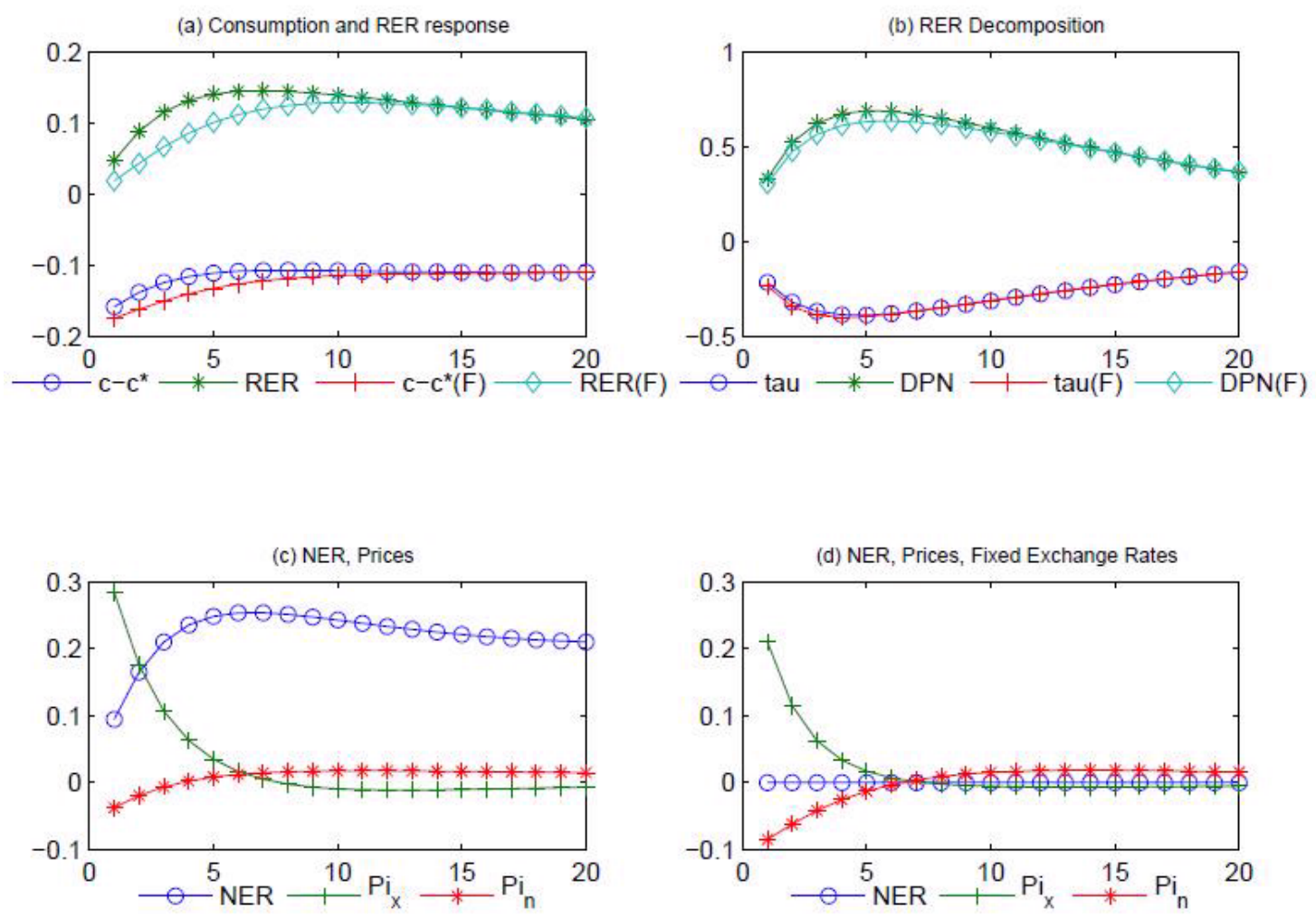

Notes: The figures present the impulse responses of home country's relative consumption and RER to a negative traded-sector productivity shock in the extended model. Panels on the top present responses under both inflation targeting regime and under a fixed exchange rate regime (denoted by letter F). Panels on the bottom show the responses of nominal exchange rate and sectoral inflation rates under inflation targeting (panel (c)) and fixed exchange rate (panel (d)) regimes. 
Figure 4: Impulse responses following a negative shock to $\mathrm{N}$ sector productivity in the extended model
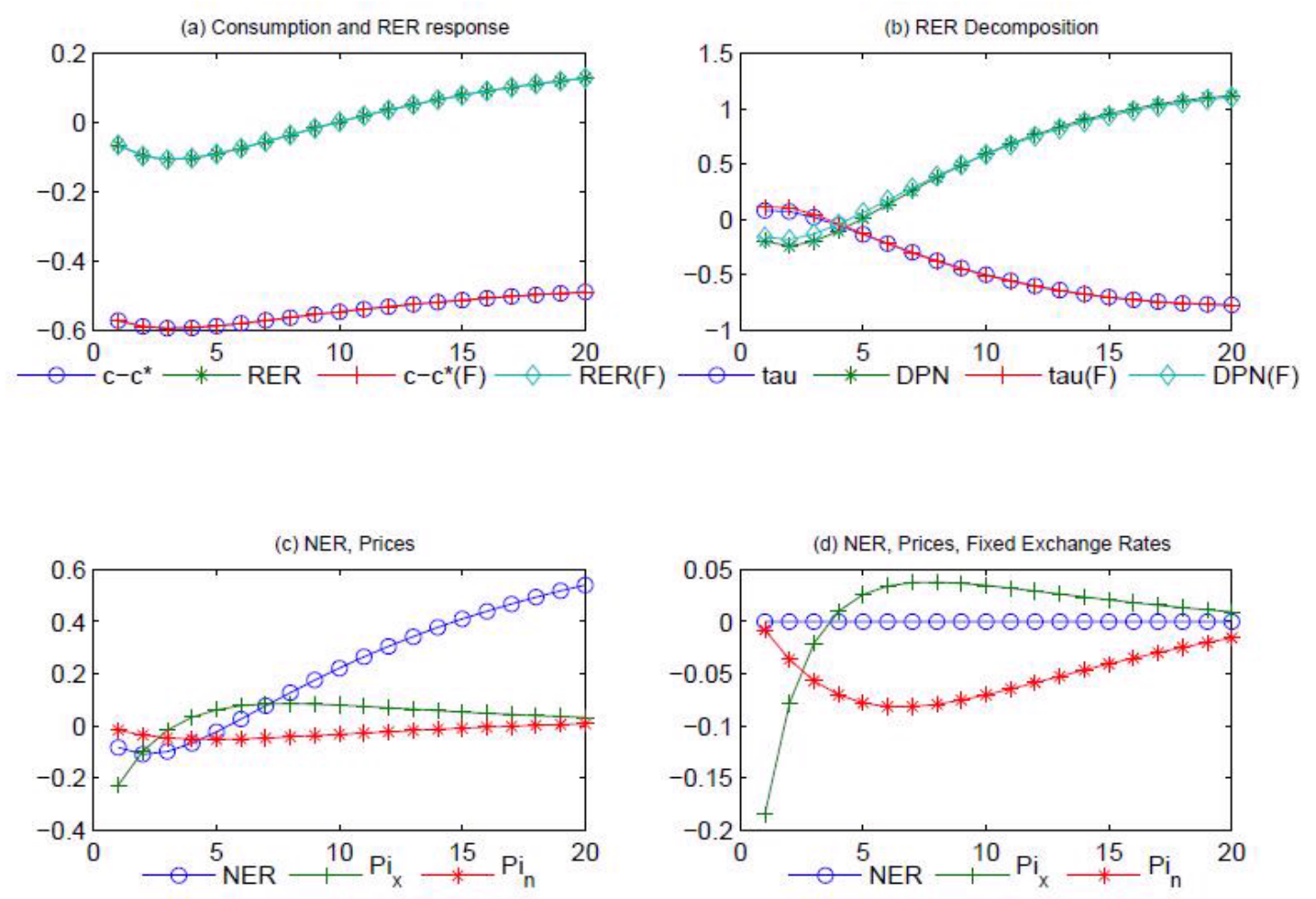

Notes: The figures present the impulse responses of home country's relative consumption and RER to a negative nontraded-sector productivity shock in the extended model. Panels on the top present responses under both inflation targeting regime and under a fixed exchange rate regime (denoted by letter F). Panels on the bottom show the responses of nominal exchange rate and sectoral inflation rates under inflation targeting (panel (c)) and fixed exchange rate (panel (d)) regimes. 
Figure 5: Impulse responses following a negative shock to $\mathrm{T}$ sector productivity in the extended model, $\lambda=5$
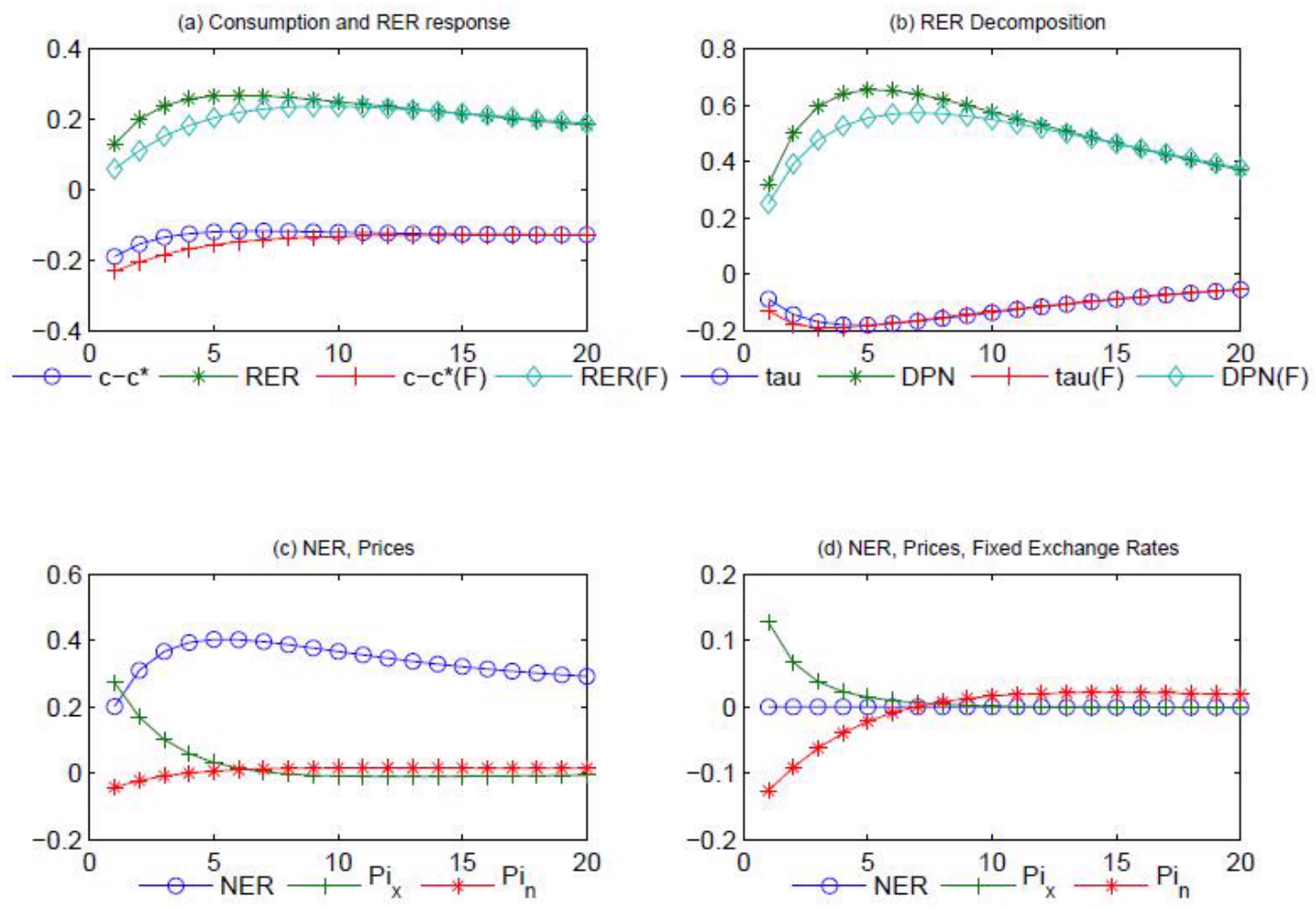

Notes: The figures present the impulse responses of home country's relative consumption and RER to a negative traded-sector productivity shock in the extended model with parameter $\lambda=5$. Panels on the top present responses under both inflation targeting regime and under a fixed exchange rate regime (denoted by letter $\mathrm{F}$ ). Panels on the bottom show the responses of nominal exchange rate and sectoral inflation rates under inflation targeting (panel (c)) and fixed exchange rate (panel (d)) regimes. 
Figure 6: Consumption-RER correlation under flexible and fixed ER regimes: Sensitivity to trade elasticity

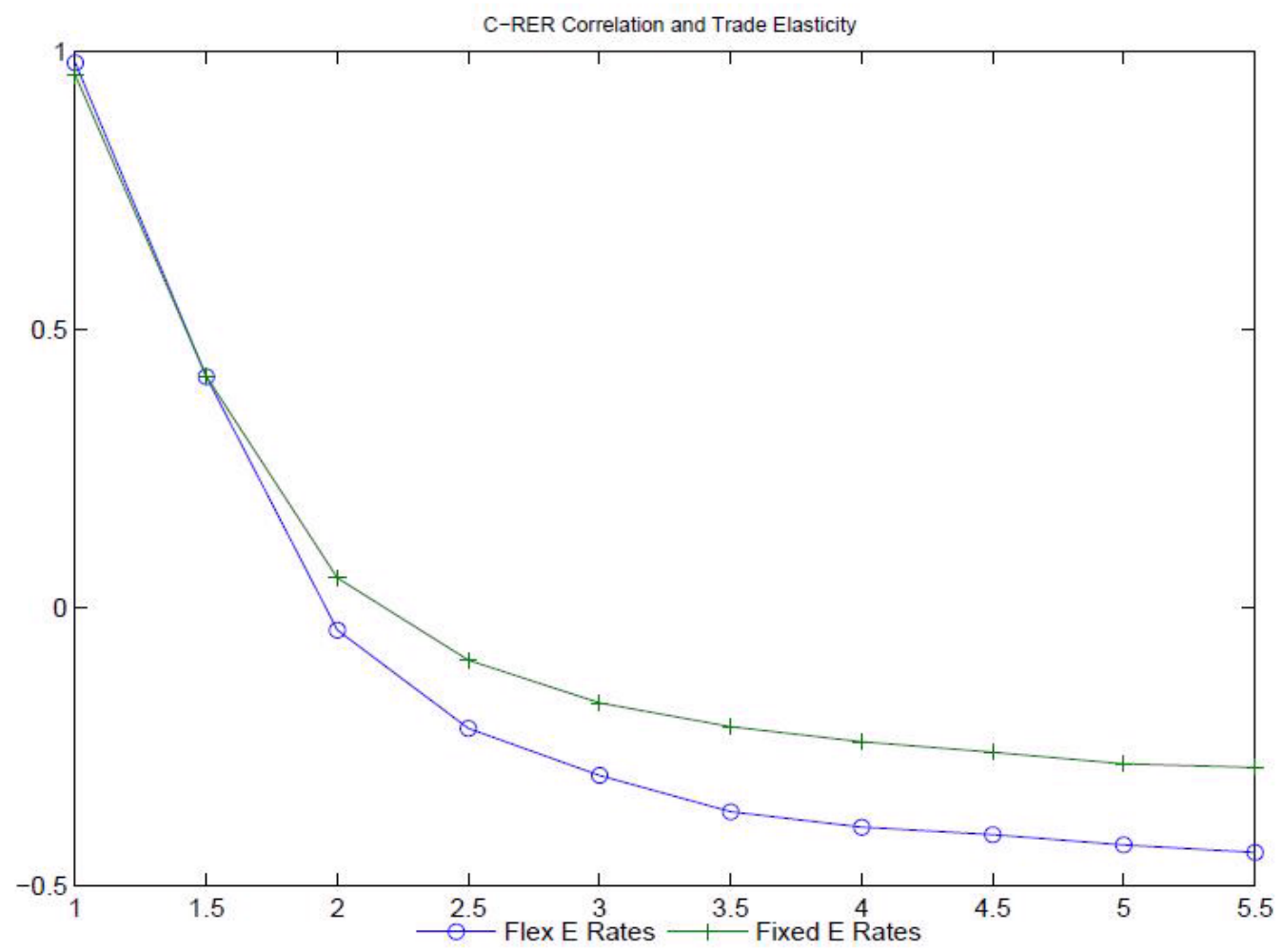

Notes: The figure presents a plot of C-RER correlation from the extended model for various values of parameter $\lambda$. Correlations are presented under both inflation targeting and fixed exchange rate regimes. 
Figure 7: Impulse responses following a negative shock to $\mathrm{T}$ sector productivity in the extended model, ex-ante pricing
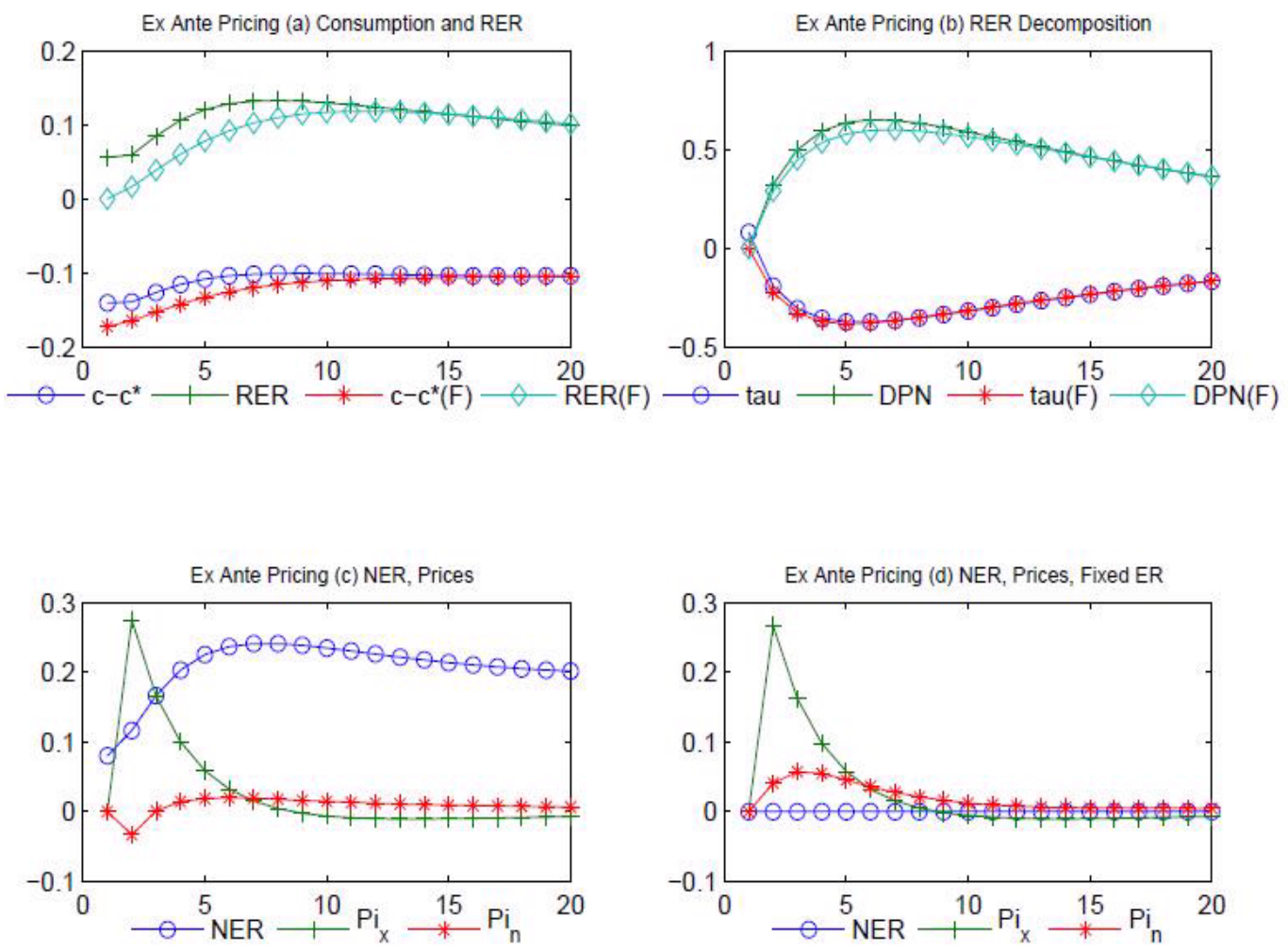

Notes: The figures present the impulse responses of home country's relative consumption and RER to a negative traded-sector productivity shock in the extended model with ex-ante pricing. Panels on the top present responses under both inflation targeting regime and under a fixed exchange rate regime (denoted by letter F). Panels on the bottom show the responses of nominal exchange rate and sectoral inflation rates under inflation targeting (panel (c)) and fixed exchange rate (panel (d)) regimes. 
Figure 8: Consumption-RER correlation under flexible and fixed ER regimes, with ex-ente pricing: Sensitivity to trade elasticity

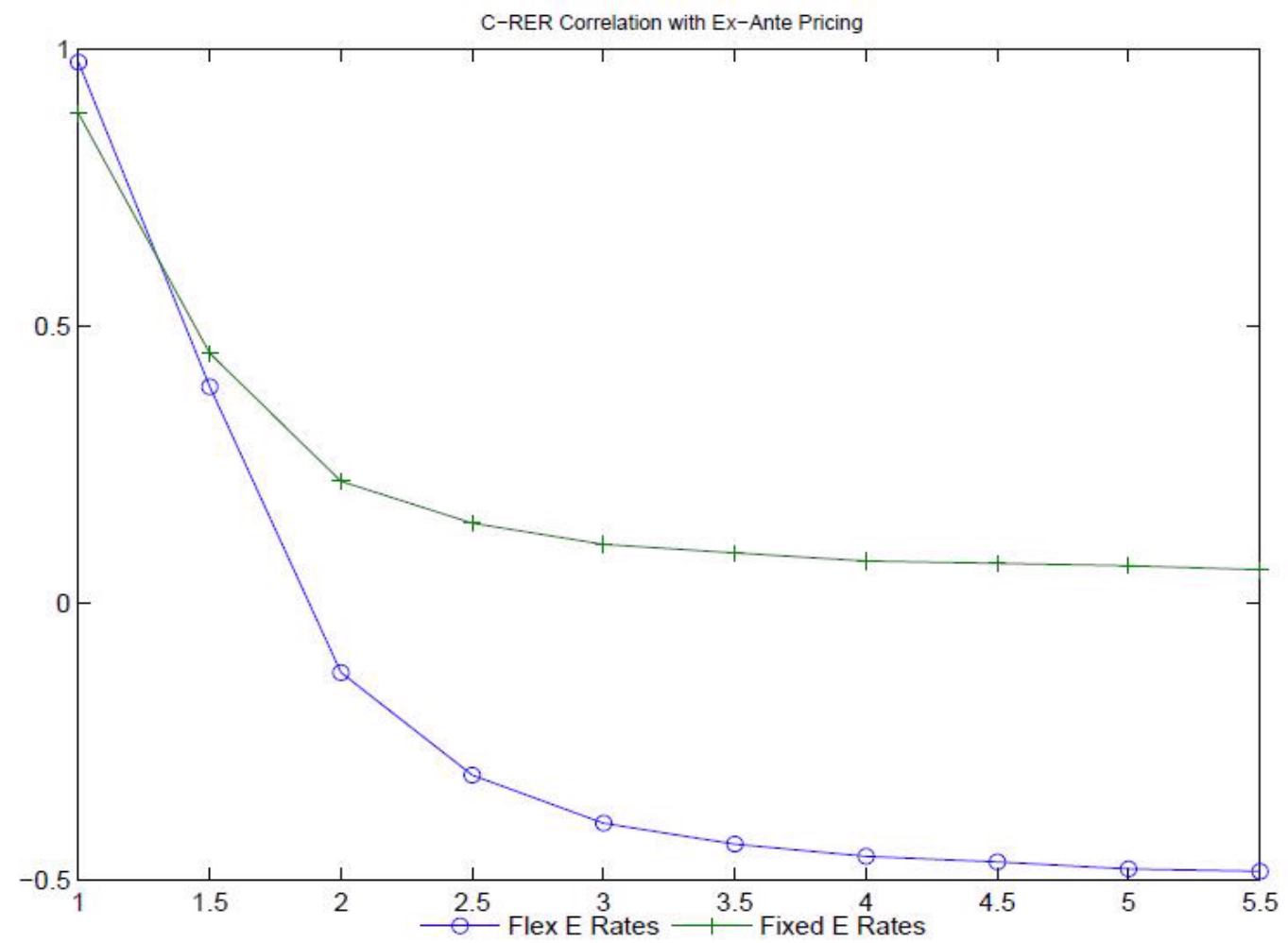

Notes: The figure presents a plot of C-RER correlation from the extended model with ex-ante pricing for various values of parameter $\lambda$. Correlations are presented under both inflation targeting and fixed exchange rate regimes. 


\section{A Appendix}

\section{A.1 Data sources}

\section{A.1.1 Regional data}

Canada: For Canada our data includes series for consumption and prices for 10 provinces and 3 territories over 1981-2007 period. All provincial data is obtained from CANSIM. For prices we used CANSIM Table 326-0021 "Consumer Price Index, by province"; for consumption, we used "Personal expenditure on consumer goods and services, Chained (2002) dollars" series. We converted consumption into real per capita terms by dividing the original series by CPI and population.

Germany: Our data for Germany covers 16 bundeslander over 1995-2007 period. Consumption series are obtained from Regional Accounts database collected by Statistische Ämter des Bundes und der Länder. The series is called "Private consumption expenditure - price-settled, concatenated - for each inhabitants in Germany 1991 to 2006 after Federal states year index $(2000=100)$ ". Price data is from GENESIS-Tabelle: 61111-0010. The series name is "Verbraucherpreisindex für Deutschland, Verbraucherpreisindex $(2005=100)$ ".

Japan: Our data for Japan covers 47 prefectures over 1990-2005 period. All series are from "The Annual Report on Prefectural Accounts" published by ESRI. Consumption series is "Private household and nonprofit consumption, real, constant prices 2000". For prices we used "GDP Deflator: Expenditure, Constant Price 2000" series. Consumption data is converted into per capita terms.

Spain: Our data for Spain covers 18 provinces over 1995-2004 period. All series are from Spanish National Statistics Institute. For consumption we used "Household Final Consumption Expenditure by Autonomous Communities". Consumption is converted into per capita terms. For prices we used "Consumer Price Index by Autonomous Communities, Spain, Annual Means" with several base years, 1992, 2001, and 2006, which we converted into a common 2001 base year.

US: Data on the Gross Domestic Product (GDP) by state is available from the Bureau of Economic Analysis (BEA). Consumption series are not available at the state level for the U.S. As in Del Negro (2002), private consumption is calculated as total retail sales in state $i$ times the ratio of total retail sales to total consumption in the US. The data on total personal consumption expenditures is obtained from the NIPA Table published by the Bureau of Economic Analysis. Total retail sales numbers are published in Sales \& Marketing Management's Annual "Survey of Buying Power" (and reproduced in the Statistical Abstract of the United States). Up until the 1999 Survey, the data correspond to the previous calendar year. Starting in 2000, the Survey data correspond to the year in which they were published. This leads to a break in the data (missing data for 1999). CPI data is not available at the state level for the U.S. ${ }^{30}$ We use data from Del Negro (2002) up to 1995. From 1996 onwards, we follow del Negro's procedure as closely as possible to extend the series.

\footnotetext{
${ }^{30}$ Gross state product deflators currently in use are constructed taking into account differences in the product mix of states, but using national price data.
} 


\section{A.1.2 International data}

To perform analysis in Section 2.3.3 we use a sample of 12 European Union (EU) member states during 1974-2007 period. The aggregate series for consumption are taken from Penn World Table 6.2 (Heston, Summers, and Aten, 2006). In particular, we used "Real gross domestic product per capita: CGDP" series in combination with "Consumption Share of CGDP: CC" series to obtain our measure of real per capita consumption for each country. The components of the RER are obtained from the following sources: (i) nominal exchange rate series are period averages calculated as local currency units per US $\$$, and are from IMF's International Financial Statistics (IFS) database; (ii) prices for EU countries in our sample are obtained from SourceOECD database and are consumer price index (CPI) series with base year of 2005 .

\section{A.2 Model derivations}

Preferences of the home country are defined as in (3.7) of the text, where the composite consumption term is defined as: $C_{t}=\Phi C_{H t}^{v / 2} C_{F t}^{1-v / 2}, v \geq 1$. In turn, $C_{H}$ and $C_{F}$ are defined over the range of home and foreign differentiated goods with elasticity of substitution $\theta$ between goods, so that:

$$
C_{H}=\left[\int_{0}^{1} C_{H}(i)^{1-\frac{1}{\theta}} d i\right]^{\frac{1}{1-\frac{1}{\theta}}}, \quad C_{F}=\left[\int_{0}^{1} C_{F}(i)^{1-\frac{1}{\theta}} d i\right]^{\frac{1}{1-\frac{1}{\theta}}}, \theta>1 .
$$

The price indices for home and foreign consumption composites are then defined as:

$$
P_{H}=\left[\int_{0}^{1} P_{H}(i)^{1-\theta} d i\right]^{\frac{1}{1-\theta}}, \quad P_{F}=\left[\int_{0}^{1} P_{F}(i)^{1-\theta} d i\right]^{\frac{1}{1-\theta}},
$$

while the aggregate $(\mathrm{CPI})$ price index for the home country is $P=P_{H}^{\frac{v}{2}} P_{F}^{1-\frac{v}{2}}$.

The household's implicit labour supply is determined by the condition:

$$
C_{t}^{-\sigma} W_{t}=P_{t} N_{t}^{\phi}
$$

The risk-sharing condition is given by

$$
\xi_{t} C_{t}^{-\sigma}=\xi_{t}^{*} C_{t}^{*-\sigma} T_{t}^{v-1}
$$

where $T=\frac{S P_{F}^{*}}{P_{H}}$.

The Euler equation for nominal bond pricing is given by:

$$
\frac{U_{C}\left(C_{t}, \xi_{t}\right)}{P_{t}}=E_{t} \beta \frac{U_{C}\left(C_{t+1}, \xi_{t+1}\right)}{P_{t+1}} R_{t+1}
$$

Foreign household preferences and choices can be defined exactly symmetrically. The foreign 
representative household has weight $v / 2,(1-v / 2)$ on the foreign (home) composite good in preferences.

Firm $i$ in the home economy uses the production function:

$$
Y_{t}(i)=A_{t} N_{t}(i)
$$

The home firm has period $t$ profits defined by $\Pi_{t}(i)=P_{H t}(i) Y_{t}(i)-W_{t} H_{t}(i)\left(1-s_{t}\right)$, where $s_{t}$ is a wage subsidy offered to each home firm by the home government, financed with lump-sum taxation. When it can adjust its price, the home firm sets the new price, denoted $\widetilde{P}_{H t}(i)$, so as to maximize the present value of profits evaluated using the stochastic discount factor $m_{t+j}=\frac{P_{t}}{U_{C}\left(C_{t}, \varepsilon_{t}\right)} \frac{U_{C}\left(C_{t+j}, \xi_{t+j}\right)}{P_{t+j}}$. This leads to the optimal price setting condition as follows:

$$
\widetilde{P}_{H t}(i)=\frac{\theta}{\theta-1}\left(1-s_{t}\right) \frac{E_{t} \sum_{j=0} m_{t+j} \kappa^{j} \frac{W_{t+j}}{A_{t+j}} Y_{H t+j}(i)}{E_{t} \sum_{j=0} m_{t+j} \kappa^{j} Y_{H t+j}(i)} .
$$

All home firms that can adjust their price choose the same price. In the aggregate, the price index for the home good then follows the process given by:

$$
P_{H t}=\left[(1-\kappa) \widetilde{P}_{H t}^{1-\theta}+\kappa P_{H t-1}^{1-\theta}\right]^{\frac{1}{1-\theta}} .
$$

The optimal subsidy will be set so as to offset the monopoly markup exactly, so that $s=1 / \theta$ will obtain in each country for all periods.

The home country monetary policy follows a modified Taylor rule, given by equation (3.12). The foreign monetary authority follows an analogous rule, except it does not target the nominal exchange rate.

Each home country firm $i$ faces demand for its good from home consumers, foreign consumers and its home government. We can define equilibrium in the market for good $i$ as

$$
Y_{H t}(i)=\left(\frac{P_{H t}(i)}{P_{H t}}\right)^{-\theta}\left[\frac{v}{2} \frac{P_{t}}{P_{H t}} C_{t}+\left(1-\frac{v}{2}\right) \frac{S_{t} P_{t}^{*}}{P_{H t}} C_{t}^{*}\right],
$$

Let $x=\ln \left(X_{t} / \bar{X}\right)$ be the $\log$ deviation of any variable from its steady state (except for inflation and nominal interest rates, which are in levels). Taking a linear approximation of (A1), (3.10) and (3.11) around the zero inflation steady state, we derive the standard forward looking inflation equation, given by:

$$
\pi_{H t}=k\left(\phi y_{H t}+\sigma c_{t}+\left(1-\frac{v}{2}\right) \tau_{t}-(1+\phi) a_{t}\right)+\beta E_{t} \pi_{H t+1}
$$

where $k=\frac{(1-\beta \kappa)(1-\kappa)}{\kappa}$.

Using (A2), (3.13) aggregated across all firms $i$, and the equivalent for the foreign country, we 
can solve for $c_{t}$ and $\tau_{t}$ in terms of $y_{H t}, y_{F t}^{*}, \varepsilon_{t}$, and $\varepsilon_{t}^{*}$. This gives:

$$
\begin{gathered}
c_{t}=\frac{v(2-v)}{2 D}\left(\varepsilon_{t}-\varepsilon_{t}^{*}\right)+\frac{n_{t}(D+v-1)}{2 D}+\frac{n_{t}^{*}(D-(v-1))}{2 D} \\
c_{t}^{*}=-\frac{v(2-v)}{2 D}\left(\varepsilon_{t}-\varepsilon_{t}^{*}\right)+\frac{n_{t}(D+v-1)}{2 D}+\frac{n_{t}^{*}(D-(v-1))}{2 D} \\
\frac{\tau_{t}}{2}=-\frac{(v-1)}{D}\left(\varepsilon_{t}-\varepsilon_{t}^{*}\right)+\frac{\sigma\left(n_{t}-n_{t}^{*}\right)}{D}
\end{gathered}
$$

Here, we define $D=\sigma v(2-v)+(1-v)^{2}$. Then, using (A9) -(A11), re-writing (A8), we have

$$
\left.\pi_{H t}=k\left[(\phi+\omega(1+D)) y_{H t}+y_{F t} \omega(D-1)\right)+\vartheta\left(\varepsilon_{t}-\varepsilon_{t}^{*}\right)-(1+\phi) a_{t}\right]+\beta E_{t} \pi_{H t+1}
$$

where $\omega=\sigma / 2 D$, and $\vartheta=\frac{(2-v)(v(\sigma-1)+1)}{2 D}$. Thus, domestic inflation is driven by both home and foreign output, preference shocks, and home productivity shocks.

In a similar manner, we can derive the 'dynamic IS equation', using (A9)-(A11) and (3.9). This gives

$$
\begin{aligned}
& E_{t}\left(y_{H t+1}-y_{H t}\right)(D+1)+E_{t}\left(y_{F t+1}^{*}-y_{F t}^{*}\right)(D-1) \\
& -E_{t}\left(\varepsilon_{t+1}-\varepsilon_{t}\right) \frac{(D+v-1)}{\sigma}-E_{t}\left(\varepsilon_{t+1}^{*}-\varepsilon_{t}^{*}\right) \frac{(D-v+1)}{\sigma} \\
= & \omega^{-1} E_{t}\left(r_{t}-\pi_{H t+1}\right)
\end{aligned}
$$

An identical set of derivations gives the equations for the foreign economy as:

$$
\begin{gathered}
\left.\pi_{F t}^{*}=k\left[(\phi+\omega(1+D)) y_{F t}+y_{H t} \omega(D-1)\right)-\vartheta\left(\varepsilon_{t}-\varepsilon_{t}^{*}\right)-(1+\phi) a_{t}^{*}\right]+\beta E_{t} \pi_{F t+1}^{*} \\
E_{t}\left(y_{F t+1}-y_{F t}\right)(D+1)+E_{t}\left(y_{H t+1}-y_{H t}\right)(D-1) \\
\quad-E_{t}\left(\varepsilon_{t+1}^{*}-\varepsilon_{t}^{*}\right) \frac{(D+v-1)}{\sigma}-E_{t}\left(\varepsilon_{t+1}-\varepsilon_{t}\right) \frac{(D-v+1)}{\sigma} \\
=\omega^{-1} E_{t}\left(r_{t}^{*}-\pi_{F t+1}^{*}\right)
\end{gathered}
$$

This system may be solved for the variables $y_{H t}, y_{F t}, \pi_{H t}$, and $\pi_{F t}^{*}$. Following this, we may solve for (3.21)-(3.22) in the text. 